\title{
Financiamento privado de campanha eleitoral: o agronegócio bancando a queda do Código Florestal brasileiro de 1965 $^{1}$
}

\author{
Private financing of electoral campaigns: the agribusiness funding the repeal of the Brazilian \\ Forest Act of 1965
}

\author{
Paulo Roberto Cunha ${ }^{2}$ \\ Neli Aparecida de Mello-Thèry ${ }^{3}$
}

\begin{abstract}
Resumo
Até o ano de 2015, o financiamento privado de campanhas eleitorais era uma das formas de mobilização política dos atores individuais e dos grupos de interesses econômicos. Partindo desse pressuposto, o objetivo deste artigo é demonstrar como o agronegócio e outros interesses organizados contribuíram decisivamente no processo político de desmonte do Código Florestal Brasileiro de 1965, por intermédio de significativa quantia doada em 2006 às campanhas eleitorais de políticos ruralistas que, em 2010, aprovaram um projeto considerado o embrião da Nova Lei Florestal.

Palavras-chaves: Código Florestal Brasileiro. Agronegócio. Lobby. Financiamento privado de campanha eleitoral.
\end{abstract}

\begin{abstract}
Until 2015, private financing of electoral campaigns was one of the forms of political mobilization of individual players and economic interest groups. Based on this assumption, the objective of this article is to demonstrate how agribusiness and other special interests decisively contributed to the political process of dismantling the Brazilian Forest Code of 1965 through significant donations, in 2006, to finance the electoral campaigns of rural caucus members, who, in 2010, approved a project considered to be the embryo of the New Forest Law.
\end{abstract}

Keywords: Brazilian Forest Act. Agribusiness. Lobby. Private financing of electoral campaigns.

\section{Introdução}

\footnotetext{
${ }^{1} \mathrm{O}$ presente artigo é fruto da dissertação de mestrado "O Código Florestal e os processos de formulação do mecanismo de compensação de reserva legal (1996-2012): ambiente político e política ambiental”, defendida pelo autor em 2013, no Programa de Pós-graduação em Ciência Ambiental da Universidade de São Paulo (Procam/USP) e sob orientação da coautora. Uma versão do texto foi apresentada no 41 ${ }^{\circ}$ Encontro Anual da Anpocs, realizado em outubro de 2017.

${ }^{2}$ Doutorando e mestre em Ciência Ambiental pelo Programa de Pós-graduação em Ciência Ambiental da Universidade de São Paulo (Procam/USP). Professor de direito ambiental e ciência política do bacharelado em direito do Centro Universitário Padre Anchieta (Jundiaí-SP). E-mail: paulorobertocunha@usp.br.

${ }^{3}$ Doutora em Geografia Humana (USP; Paris X - Nanterre). Profa. Dra. da Escola de Artes, Ciências e Humanidades (Each) e do Programa de Pós-graduação em Ciência Ambiental (Procam) da Universidade de São Paulo.
} 
A revogação Código Florestal Brasileiro (CFB/1965) (Lei Federal n 4.771/1965) e sua substituição pela Lei Federal $n^{\circ}$ 12.651/2012 (doravante denominada de Nova Lei Florestal) foi o resultado de um conflituoso processo político-legislativo, que envolveu a interação complexa de múltiplos elementos, e cujo ápice se deu entre 2009 e 2012.

Este trabalho parte de duas premissas: (i) a Nova Lei Florestal representa um retrocesso na política ambiental nacional em relação ao antigo e revogado CFB/1965, como prova Soares-Filho (2013) e outros pesquisadores que se pronunciaram durante a tramitação do projeto de lei, como condensado em Cunha (2013); (ii) no processo político-legislativo em tela, prevaleceram as proposições e as influências dos grupos de interesses e atores individuais ligados ao agronegócio e outros interesses associados, empenhados na diminuição das exigências ambientais e em anistias às infrações cometidas pelos seus sequazes, como demonstrado em Cunha (2013).

Como explicar a hegemonia de um setor econômico no processo de tomada de decisão que culminou na flexibilização de normas ambientais, quando a Constituição Federal de 1988 (CF/1988) preconiza o dever do poder público em preservar o meio ambiente ecologicamente equilibrado para as presentes e futuras gerações e a vedados retrocessos ambientais, como argumentam Nogueira (2013) e Benjamin (2012)?

Para responder à pergunta, este artigo foca no agronegócio e outros interesses associados e na mobilização desses setores por intermédio de financiamento de campanha eleitoral, considerado uma forma de recurso político ${ }^{4}$.

Assim, apropriando-se de aspectos teóricos da análise de políticas públicas, este trabalho examina uma fração do processo político (politics) de revogação do CFB/1965, a fím de demonstrar que o agronegócio e outros atores associados influenciaram na tomada de decisão, por intermédio de financiamento privado de campanha de políticos ruralistas que, por sua vez, atenderam positivamente às pretensões daqueles setores.

A metodologia empregada consistiu em pesquisas bibliográficas e levantamentos de dados no Tribunal Superior Eleitoral, na Câmara dos Deputados, na Receita Federal e em outras instituições. Realizou-se, ainda, um recorte temporal específico ao concentrar a análise em uma das arenas políticas do processo em relevo: a Comissão Especial Temporária do Código Florestal, instalada na

\footnotetext{
${ }^{4}$ Citando alguns autores, Mancuso (2004, p. 76) explica que "recurso político é tudo que possui valor em uma sociedade e pode ser utilizado pelo ator com o objetivo de moldar uma decisão política", como o dinheiro, posição social, conexões com ocupantes de cargos públicos, informação, boa reputação, tempo, popularidade, legitimidade, legalidade etc.
} 
Câmara Federal em 2009 e que, em julho de 2010, aprovou um projeto de lei com grandes prejuízos ambientais, considerado o embrião dos retrocessos contidos na Nova Lei Florestal ${ }^{5}$.

Com relação aos políticos ruralistas, o presente trabalho considera aqueles que pertencem às bancadas que representam os "interesses da classe dos proprietários de terra no Brasil", ou seja, os políticos que "protagonizam a questão agrária brasileira e estão inseridos nas dinâmicas territoriais de apropriação de terras em meio à lógica do desenvolvimento desigual e combinado no modo capitalista de produção na agricultura" (COSTA; OLIVEIRA, 2011, p. 2).

A bancada ruralista do Congresso Nacional é um grupo suprapartidário, informal e de grande eficiência, cuja finalidade é atender as pautas do empresariado rural, podendo até se posicionar contra o governo para ver seus pleitos satisfeitos (DIAP, 1998; 2006, p. 31). Segundo o deputado Ivan Valente (PSOL/SP), a bancada ruralista tem representação nas coalizões do governo e da oposição da direita e é hegemonizada por um grupo de grandes produtores; apesar de representarem os interesses dos exportadores de commodities, os ruralistas falam indevidamente em nome dos pequenos (CÂMARA DOS DEPUTADOS, 2010).

O mapeamento dos parlamentares ruralistas no presente trabalho é fruto do cruzamento entre: (i) a análise da votação da Comissão Especial do CFB/1965, ocorrida em 06/07/2010; e (ii) a lista produzida por Costa (2012), que reúne 374 ruralistas que passaram pelo Congresso Nacional, eleitos nos pleitos de 1994 a 2010, cuja condição material por ela investigada permite afirmar que se trata de "um conjunto de políticos capitalistas industriais, capitalistas comerciais, proprietários de terras (grileiros e latifundiários)" (COSTA, 2012, p. 20).

Em suma, a metodologia adotada por Costa (2012, p. 21-25) é a seguinte:

(i) Adoção das "Radiografias do Congresso", do Departamento Intersindical de Assessoria Parlamentar (Diap), desde a eleição de 1994 até 2010, que classifica como ruralista não só o parlamentar proprietário rural ou da área de agronegócios, mas também "aquele que assuma sem constrangimento a defesa dos pleitos da bancada, não apenas em plenários e nas comissões, mas em entrevistas à imprensa e nas manifestações de plenário" (DIAP, 2006, p. 31) - pela lista do Diap, Costa (2012) enumerou 299 ruralistas;

(ii) Identificação da "condição de proprietário de terra ou capitalista da agricultura" dos parlamentares que não assumiram pertencer à bancada ruralista, mas que "no plano da representação da classe não se oporiam ao projeto de manutenção do poder de tal bancada no Congresso Nacional

\footnotetext{
5 Após a Comissão Especial (2010), o projeto de lei foi sendo aprovado, com modificações, pelo plenário da Câmara (maio/2011), pelo Senado (dez./2011) e novamente pela Câmara (maio/2012). A sanção presidencial, com vetos parciais, na Lei Federal $n^{\circ}$ 12.651/2012, ocorreu em maio/2012. Apesar de ter sido quase que totalmente modificado, a essência do projeto de lei aprovado na Comissão Especial permaneceu na Lei Federal no 12.651/2012.
} 
e que reúnem todas as condições materiais de um ruralista" (COSTA, 2012, p. 21). Nesse contexto, a referida pesquisadora analisou as declarações de bens entregues por tais congressistas à Justiça Eleitoral nos anos de 2002 e 2010, que resultou em um acréscimo de mais 74 parlamentares "expoentes da elite agrária", que foram denominados de "parlamentares ruralistas identificados" (COSTA, 2012, p. 20-21).

E, finalmente, para selecionar as empresas do agronegócio que financiaram as campanhas eleitorais de políticos que, por sua vez, aprovaram uma lei de retrocesso ambiental, considerou-se, inicialmente, as eleições de 2006 e os deputados que participaram da votação da Comissão Especial do CFB/1965 que aprovou o embrião da Nova Lei Florestal, em julho de 2010.

Em seguida, foram examinadas as empresas e grupos econômicos que fizeram contribuições para tais parlamentares a partir de $\mathrm{R} \$ 1.000,00$ e cujas atividades estavam voltadas, de forma geral, para a cadeira produtiva agropecuária, levando em conta "sua articulação com o mundo dos grandes negócios", tal como apregoa Arruda (2007, p. 4-5; 9). A descrição das atividades empresariais foi obtida lançando o número do CNPJ do doador (disponível na lista dos financiadores de campanhas do TSE) na página eletrônica da Receita Federal.

Em muitos casos, realizaram-se investigações em diversas páginas eletrônicas de empresas, em busca de informações a respeito das suas atividades produtivas e mercantis ou de eventuais subsidiárias, subordinadas ou filiais do mesmo grupo econômico. Nessas situações, foi considerada pertencente ao agronegócio a pessoa jurídica que, mesmo não tendo atividade diretamente vinculada à cadeia agropecuária, possuísse relações societárias com empresas do agronegócio.

Foram incluídas ainda nessa classificação as pessoas jurídicas que se declararam comprometidas com o agronegócio ou aquelas associadas a algum grupo de interesse representativo do setor, como a CNA ou a Associação Brasileira do Agronegócio (Abag), além, é claro, da própria organização, quando fosse doadora de campanha eleitoral.

As empresas com as seguintes atividades também foram consideradas como agronegócio: fabricantes de fertilizantes, processadoras de fumo e aquelas com atividade econômica exclusivamente relacionada à agropecuária (como comércio de máquinas e de insumos agropecuários e cooperativa de crédito rural).

Inclui-se ainda empresas cujas atividades estivessem diretamente vinculadas à exploração de recursos naturais em imóveis rurais e que pudessem ser beneficiadas pela flexibilização do CFB/1965, 
tais como: mineradoras ${ }^{6}$ e geradoras de energia hidrelétrica ${ }^{7}$, aqui denominadas de interesses associados. Aliás, em muitos momentos, grupos de interesses dos setores de mineração e hidrelétricas fizeram lobby pela revogação do CFB/1965, como mostrado em Cunha (2013) ${ }^{8}$.

Assim, a primeira seção deste trabalho explica os principais instrumentos do CFB/1965 e da Nova Lei Florestal, bem como justifica o argumento de que a recente lei representa um retrocesso ambiental. $\mathrm{Na}$ segunda parte apresenta os apontamentos teóricos que orientam esta pesquisa. $\mathrm{Na}$ terceira desenvolve os resultados obtidos de acordo com os objetivos traçados e os elementos teóricos e metodológicos definidos.

As evidências sintetizadas na conclusão sugerem que o financiamento de campanhas eleitorais de políticos ruralistas, por parte do agronegócio e outros interesses associados, contribuiu decisivamente na tomada de decisão e ajuda a explicar a aprovação de uma proposta que trazia benefícios a tais setores.

\section{Por que a Nova Lei Florestal é um retrocesso ambiental?}

O revogado CFB foi sancionado em 1965, mas sofreu uma série de alterações ao longo de sua vigência, especialmente nos anos de 1986, 1989, 1991 e 2000-2001, ampliando-se os dispositivos de proteção ambiental e adequando-o à nova ordem constitucional introduzida no Brasil pela CF/19889 .

O CFB/1965 atualizado disciplinava o uso do solo para proteção dos elementos naturais situados em imóveis rurais, principalmente aqueles de domínio privado, visando diminuir os impactos negativos causados pela retirada da vegetação nativa. Seus principais instrumentos eram: as áreas de preservação permanente (APP) e de reserva legal (RL).

As APPs eram faixas de vegetação estabelecidas independentemente do tamanho da propriedade, em razão da topografia ou do relevo, geralmente ao longo dos cursos d'água, nascentes,

\footnotetext{
${ }^{6}$ A mineração, pela Resolução Conama no 369/2006, é uma das atividades por meio do qual o órgão ambiental pode (poder discricionário) autorizar intervenção ou supressão de vegetação em APP. Essa autorização é feita em processo de licenciamento ambiental e depende do cumprimento de uma série de exigências, dentre as quais atendimento às normas de RL e o cumprimento por parte do empreendedor de medidas mitigadoras e compensatórias, que consistem na efetiva recuperação ou recomposição de APP na mesma sub-bacia do empreendimento (BRASIL, 2006).

${ }^{7}$ O CFB/1965 impunha às empresas geradoras de energia hidrelétrica a obrigação de recuperar as faixas de 100 metros ao redor dos reservatórios, consideradas APPs. Portanto, o conceito de "áreas consolidadas" do PL Rebelo, que foi incorporada à Nova Lei Florestal, interessava ao setor.

${ }^{8}$ Em Cunha (2013, apêndice A) é possível consultar uma descrição detalhada a respeito das atividades de cada uma das referidas empresas e os motivos pelos quais elas foram classificadas como pertencentes ao agronegócio e interesses associados.

${ }^{9}$ Refere-se à inovadora perspectiva de proteção ao meio ambiente (Art. 255) e a função social da propriedade rural (Art. 186), que passou a exigir a utilização apropriada dos recursos naturais disponíveis.
} 
topos e encostas de morros, destinadas à manutenção da qualidade dos solos, das águas, à preservação da paisagem, das áreas de recarga, da estabilidade geológica e da biodiversidade, bem como à formação de corredores ecológicos visando ao fluxo gênico de fauna e flora. Nas palavras de Metzger (2010, p. 95), as APPs “evitam a erosão de terrenos declivosos e a colmatagem dos rios, asseguram os recursos hídricos" e prestam serviços ambientais.

A RL, por sua vez, compreende uma fração obrigatória e variável da área total de um imóvel rural, não suscetível de exploração que comprometa sua integridade, onde é vedado corte raso da vegetação. Os percentuais mínimos de RL que um imóvel rural deve manter são estabelecidos conforme sua localização no território brasileiro: $80 \%$ se o imóvel estiver situado em região de floresta na Amazônia Legal; 35\% no cerrado localizado na Amazônia Legal; 20\% nas demais regiões do país.

De um modo geral, as regras do CFB/1965 sempre foram ignoradas pelo setor produtivo rural, sendo que os números dessa "desobediência civil” (IRIGARAY, 2007, p. 54; 61) são divergentes, mas expressivos. Silva et al. (2011, p. 10) acentuavam que 83 milhões de hectares (ha) de áreas protegidas pelo CFB/1965 estavam irregularmente ocupadas. Para Sparoveck et al. (2011, p. 120), 43 milhões de ha de APPs estavam em situação de não conformidade, ou seja, com déficit de vegetação natural, e havia uma ausência de 42 milhões de ha de vegetação necessária para respeitar a RL.

A Nova Lei Florestal manteve as APPs e RLs do CFB/1965, mas trouxe inovações que abrandaram a proteção ambiental proporcionada por tais instrumentos, como por exemplo: as RLs desmatadas de acordo com a lei da época não precisam mais ser recuperadas (Art. 68); as propriedades rurais com até 4 módulos fiscais que detinham, em 22/07/2008, RL em porcentagem inferior ao mínimo estabelecido não precisam recuperar esse déficit (Art. 67); possibilidade de plantio intercalado de espécies exóticas ou frutíferas em até 50\% da área a ser recuperada de RL; redução das exigências de recuperação de APPs, inclusive permitindo, em determinadas circunstâncias, a continuidade de certas atividades consolidadas até 22/07/2008 (BRASIL, 2012).

Diante desse cenário, considera-se que a nova lei representa um significativo retrocesso ambiental. Comparando a Lei Federal no 12.651/2012 com o revogado CFB/1965, percebe-se uma redução do passivo ambiental de aproximadamente 50 para 21 milhões de hectares em todo país, algo como 58\% (SOARES-FILHO, 2013), conforme revela o Gráfico 1 a seguir: 


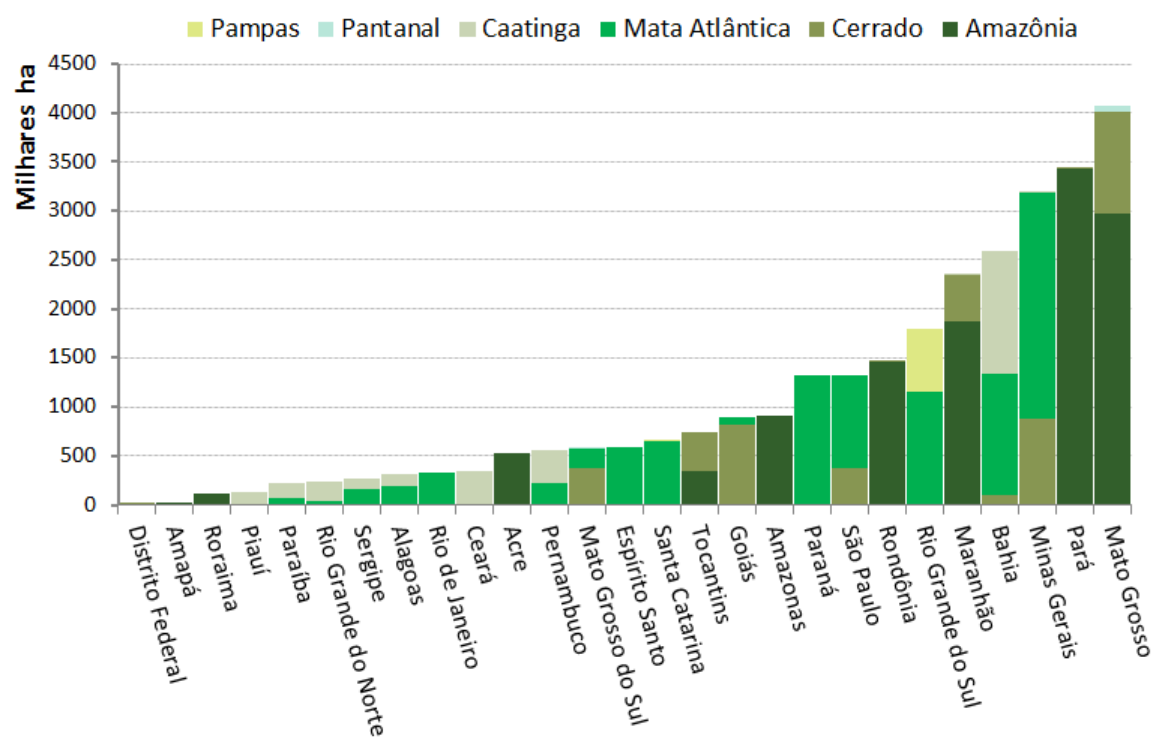

GRÁFICO 1 - REDUÇÃO DO PASSIVO FLORESTAL DEVIDO À REVISÃO DO CFB/1965 FONTE: SOARES FILHO (2013).

O espírito do CFB/1965 atualizado era restaurar a paisagem degradada, enquanto a atual Lei Florestal, apesar de obrigar a recomposição da vegetação em alguns casos, trabalha com a lógica de legalização das áreas desmatadas e é por isso que o estado do Mato Grosso, por exemplo, deixará de recuperar um pouco mais de 4 milhões de ha, como mostra o gráfico anterior.

\section{Apontamentos teóricos: a produção de políticas públicas, o lobby dos grupos econômicos e o financiamento privado de campanha eleitoral}

A produção de políticas públicas é um processo abrangente, que envolve uma gama de elementos e variáveis, como: a mobilização de recursos políticos por atores; a hegemonia, no Brasil, do Poder Executivo sobre o Legislativo, estudada por Abranches (2003) e outros; a sensibilidade do tomador de decisão, que pode ser influenciado pela opinião pública, pelo seu eleitorado, pelas diretrizes partidárias, pelas orientações dos líderes dos partidos ou coligação (MANCUSO, 2004, p. 119); o papel decisivo exercido pelas instituições sobre as interpretações e o agir dos atores (SOUZA, 2003, p. 18). No mesmo sentido, Dye (2009, p. 100-101) salienta que a maioria das políticas públicas é uma "composição de planejamento racional, incrementalismo, atividades de grupos de interesse, preferências de elites, forças sistêmicas, partida de jogo, opção pública, processos políticos e influências institucionais". Para Labra (1999, p. 136), a política pública é "resultante da 
acomodação, negociação e concertação de interesses organizados e conectados às esferas de decisão mediante arranjos formais específicos".

As decisões coletivas em processos de produção legislativa são, portanto, o resultado de multiplicidade de vários elementos, que não são apenas numerosos, mas interagem entre si de forma complexa (MANCUSO, 2007, p. 131-132). E nesse processo, a articulação de interesses entre o Estado e a sociedade é feita principalmente por intermédio de partidos políticos e de grupos de interesses (empresariais, sindicais patronais ou de empregados, ONGs, associações e outros).

Grupo de interesse, por sua vez, é "uma associação de indivíduos ou organizações ou uma instituição pública ou privada que, na base de um ou mais interesses compartilhados, procura influenciar uma política pública a seu favor"10 (THOMAS, 2004, p. 4). Klüver (2013, p. 5), citando Beyrs, Eising e Maloney (2008, p. 1106-1109) ${ }^{11}$, exclui instituições públicas da categoria de grupos de interesses, ao afirmar que três características devem estar presentes para definir um ator como tal: organização, interesse político e natureza ("status") privada. Sublinhe-se ainda que os grupos não disputam eleição, não são partidos políticos, mas possuem interesses políticos.

Grossman e Saurugger (2006, p. 11) analisam, em uma acepção mais geral, que grupo de interesse é uma organização constituída que procura influenciar os poderes políticos de forma favorável aos seus interesses.

E influência, por seu turno, é a "habilidade de um ator moldar uma decisão política na conformidade das suas preferências" (KLÜVER, 2013, p. 7, citando DÜR, 2008, p. 561 ${ }^{12}$ ), sendo que as atividades destinadas a influenciar uma decisão de política pública é chamada de lobbying, assim definido por Thomas (2004, p. 6):

A interação de um grupo ou interesse com os decisores de política pública, que pode ser feita tanto de forma direta como indireta, cujo objetivo é influenciar uma política pública já existente ou criar relações visando à formação de uma política futura, a fim de beneficiar aquele grupo ou interesse (tradução nossa) ${ }^{13}$.

Focando na União Europeia, Klüver (2013, p. 18) expõe que o lobbying é uma "relação de troca entre atores interdependentes", ou seja, grupos de interesses demandam a decisores vinculados

\footnotetext{
${ }^{10}$ No original: An interest group is an association of individuals or organizations or a public or private institution that, on the basis of one or more shared concerns, attempts to influence public policy in its favor (THOMAS, 2004, p, 4).

${ }^{11}$ BEYRS, Jan; EISING, Rainer; MALONEY, Willian. Researching Interest Group Politics in Europe and Elsewhere: much we study, little we know? West European Politics, v. 31, n. 6, p. 1103-1128, 2008.

${ }^{12}$ DÜR, Andreas. Measuring Interest Group Influence in the EU: a note on methodology. European Union Politics, v. 9 , n. 4 , p. $559-576$.

${ }^{13}$ No original: The interaction of a group or interest with policy makers, either directly or indirectly, that has a view to influencing current policy or creating a relationship conducive to shaping future policy to the benefit of that group or interest (THOMAS, 2004, p. 6).
} 
a instituições que, por sua vez, reivindicam aos grupos informações políticas relevantes, apoio de cidadãos e poder econômico.

Os grupos de interesses praticam lobbying por intermédio de algumas atividades, como: (i) obter acesso aos decisores de políticas públicas; (ii) criar atitudes entre os decisores que conduzam aos objetivos do grupo; (iii) influenciar decisores para favorecer o grupo (THOMAS, 2004, p. 140-144). E, para tanto, uma das táticas utilizadas se trata das "contribuições ao fundo de campanha para candidatos e partidos", como menciona o mesmo autor ao se referir aos Estados Unidos, que equivale ao financiamento de campanha eleitoral que era permitido no Brasil até $2015^{14}$.

A prática lobbying, incluindo o financiamento de campanha, ocorre não só coletivamente, por intermédio dos grupos de interesses, como também por atores individualmente considerados. Por isso, considerando o agronegócio, o presente estudo foca tanto nos grupos de interesses, tendo como exemplo a Confederação Nacional da Agricultura e Pecuária (CNA) - entidade de cúpula do agronegócio - e a Confederação Nacional das Indústrias (CNI), além das federações associadas, como também nos atores individuais, exemplificados pelas empresas Bunge, Friboi, Votorantim, Aracruz e Amaggi, pertencentes ao agronegócio, segundo Oliveira (2007, p. 148).

O termo agronegócio está espelhado no conceito de agribusiness, criado em 1957 por John Davis e Ray Goldeberg (ARRUDA, 2007, p. 3), e entendido como:

o conjunto de todas as operações e transações envolvidas desde a fabricação dos insumos agropecuários, das operações de produção nas unidades agropecuárias, até o processamento e distribuição e consumo dos produtos agropecuários in natura ou industrializados (ARAUJO, 2007, p. 16, citando RUFINO, 1999 ${ }^{15}$ ).

No Brasil, o termo agronegócio é usado com diferentes interpretações, mas, em linhas gerais, sua concepção está associada à transformação da dimensão produtiva, anteriormente concentrada "dentro da porteira", passando a considerar os seguimentos que compõem o "antes da porteira" (representados pelos fatores necessários à produção agropecuária) e o "pós-porteira" (as etapas de processamento e distribuição dos produtos aos consumidores); o agronegócio "corresponde às transações econômicas que envolvem toda a cadeia produtiva agrária" e sua inserção "num amplo

\footnotetext{
${ }^{14}$ Em setembro de 2015, o Supremo Tribunal Federal considerou inconstitucional a regra que liberava o financiamento eleitoral de campanha por pessoa jurídica, ao entender que essa prática capturava o político pelo poder econômico, caracterizando indesejada "plutocratização" do processo político.

${ }^{15}$ RUFINO, José Luís dos Santos. Origem e conceito do agronegócio. Informe Agropecuário, Belo Horizonte, Epamig, v. 20, n. 199, p. 17-19, jul./ago. 1999.
} 
sistema de commodities $^{16}$ cuja lógica atende ao processo de acumulação do capital e a sua articulação com o mundo dos grandes negócios" (ARRUDA, 2007, p. 4-5; 9). Outra característica do setor é a estratégia de aliança rentista entre os "agentes capitalistas industriais/financeiros/comerciais" e os “grandes proprietários de terras (latifundiários)" (RIBEIRO, 2009, p. 15) ${ }^{17}$.

Diante disso, é possível aplicar ao presente estudo - em particular ao agronegócio - as concepções teóricas trazidas por Mancuso (2007), ao estudar o lobby do empresariado industrial no Congresso Nacional. Para esse autor, a mobilização desse setor é "multifacetada" e distribuída em diversos momentos políticos relevantes, como a atuação junto aos partidos políticos para definir nomes que disputarão os pleitos eleitorais, sugestão ou veto de nomes para cargos públicos de indicação, a elaboração de proposições em processos decisórios definidos, discussões no âmbito das comissões legislativas, a "pressão política" consistente na "apresentação de demandas aos tomadores de decisão", intervenções nas fases de regulamentação da política pública e o financiamento de campanhas eleitorais $^{18}$ (MANCUSO, 2007, p. 84-91).

Este trabalho, portanto, considera o financiamento privado de campanhas eleitorais como uma forma de lobby dos grupos de interesses e empresas individuais do agronegócio e de outros interesses, porque parte do pressuposto de que os seus apoiados, se eleitos, serão interlocutores do financiador.

\section{A formação da Comissão Especial do CFB (2009): composição ruralista e relatoria "comunista"}

No final da primeira década dos anos 2000, setores ligados à agropecuária, capitaneados pela CNA, grupo de interesse que representa o agronegócio brasileiro, se insurgiram contra a legislação ambiental, acusando o atualizado CFB/1965 de afrontar o direito de propriedade, provocar insegurança jurídica, prejudicar a produção e carecer de base científica (TELLES DO VALLE, 2010, p. 347). Esse movimento sobreveio em decorrência de alguns fatores, dentre os quais: (i) a

\footnotetext{
${ }_{17}^{16}$ Mercadorias para atender ao mercado mundial (OLIVEIRA, 2007, p. 147).

17 Compartilha-se da visão de Fernandes (2008) a respeito da "conflitualidade 'invisível' do agronegócio", isto é, a ocultação do "caráter concentrador, predador, expropriatório e excludente" desse setor pela sua imagem de produtividade, de adoção de novas tecnologias no campo e de geração de riquezas para o país, retórica muito bem usada pelo setor na arena política de mudança do CFB/1965, escondendo, pois, a raiz desse fenômeno que é a expansão da concentração de poder e das riquezas.

${ }^{18}$ Os partidos políticos brasileiros são financiados pela contribuição de filiados e por um fundo partidário que distribui recursos públicos segundo determinados critérios. A campanha eleitoral, além de um subsídio estatal consistente na veiculação gratuita de propagandas na televisão e rádio, recebe contribuições de pessoas físicas (até $10 \%$ dos rendimentos brutos auferidos no ano anterior à eleição) e, até 2015 , recebia de pessoas jurídicas (até $2 \%$ do faturamento bruto no ano anterior da eleição).
} 
expressividade que o agronegócio ganhou na economia (KRAUSE, 2011 [informação verbal]) ${ }^{19}$; (ii) a ampliação e fortalecimento da bancada ruralista no Congresso Nacional; (iii) os movimentos contrários às ações de aprimoramento do enforcement da política ambiental daquela época ${ }^{20}$.

Na esteira desses acontecimentos, o Banco Central editou, em fevereiro de 2008, a resolução $\mathrm{n}^{\circ} 3.545$, passando a exigir comprovante de regularidade ambiental, o que incluía o cumprimento do CFB/1965, para concessão de crédito às atividades agropecuárias no bioma amazônico. Essa norma também mobilizou o agronegócio contra o CFB/1965 (CÂMARA DOS DEPUTADOS, 2010, p. 37.392).

Aos poucos, esse movimento foi ressoando no Congresso Nacional, tanto que entre os anos de 1999 a 2009 surgiram 41 projetos de lei (PL) que propunham alterar e até mesmo revogar o CFB/1965 (GANEM; ARAÚJO, 2010, p. 376-401).

Encabeçado pelo PL 1.876/1999, alguns daqueles projetos de lei foram apensados por razões regimentais, sendo que, em 2009, o então presidente da Câmara dos Deputados, Michel Temer (PMDB/SP), entendeu pela constituição de uma Comissão Especial Temporária para revisar o CFB/1965 (CÂMARA DOS DEPUTADOS, 2012).

Obedecendo aos critérios da proporcionalidade dos partidos e conforme a indicação das lideranças partidárias, a composição inicial da Comissão Especial se deu com 35 deputados, entre titulares e suplentes. Ressalta-se que o conjunto de forças daquela arena que começou a discutir a substituição do CFB/1965 era majoritariamente ruralista.

Com base na metodologia descrita na introdução, o Quadro 1, a seguir, revela que 21 dos 35 membros da composição inicial da Comissão Especial do CFB/1965 eram ruralistas e muitos deles estavam ligados a partidos da coalizão do governo Lula:

\footnotetext{
${ }^{19}$ KRAUSE, Gustavo (Gustavo Krause Gonçalves Sobrinho) [ministro do Meio Ambiente, dos Recursos Hídricos e da Amazônia Legal, de janeiro/1995 a janeiro/1999, no governo Cardoso]: depoimento concedido em entrevista pessoal (137 m.). Entrevistador: Paulo Roberto Cunha. Recife (PE), 31 jan. 2011.

${ }^{20}$ As ações de enforcement podem ser exemplificadas pela intensificação das atuações do Ministério Público e pela edição dos Decretos Federais n ${ }^{\text {os }} 6.321 / 2007$ e 6.514/2008, o primeiro autorizando o embargo de imóveis rurais da Amazônia com desmatamento ilegal e a criminalização da cadeia produtiva e o segundo aplicando multas para o descumprimento das regras de APP e RL, dentre outras.
} 


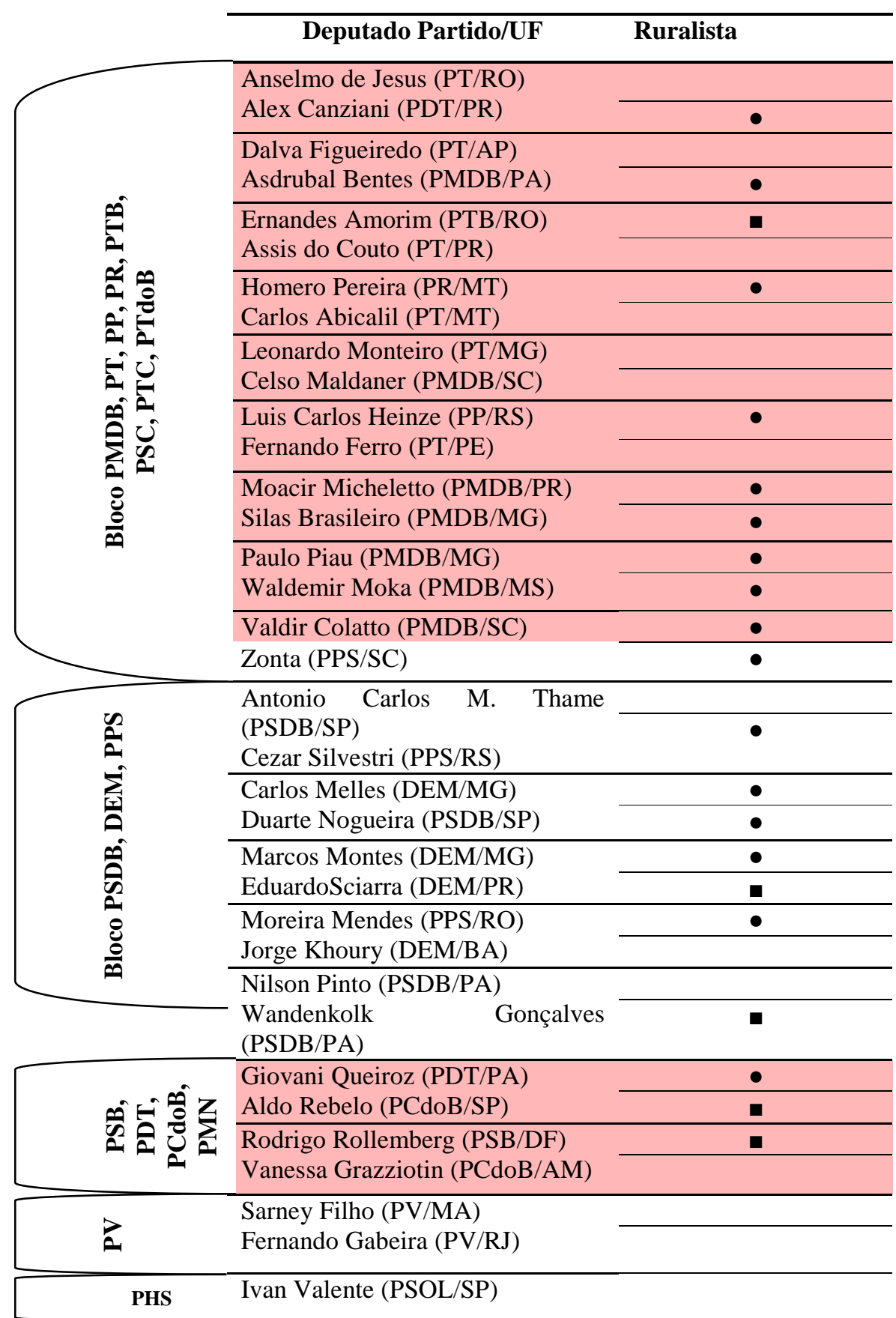

- Parlamentar ruralista incluído na lista do Diap, segundo Costa (2012, anexo C).

- Parlamentar ruralista identificado por Costa (2012) e fora da lista do Diap.

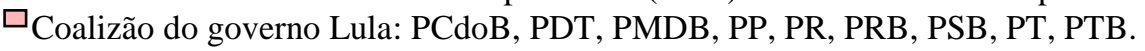

FONTE: Elaborado pelos autores. Dados extraídos de CÂMARA DOS DEPUTADOS (2009, 2011a, 2011b); PASQUARELLI (2011); COSTA (2012).

NOTA: nem todos os nomeados participaram até o final da Comissão; o primeiro nome de cada linha indica o titular e o segundo o suplente.

Admite-se algum questionamento ao qualificar Rebelo como ruralista, até porque Costa (2012) reconhece que o referido parlamentar foi incluído em sua lista apenas pelo "apoio ideológico", 
dadas as pretensões da bancada ruralista naquela oportunidade. Nessas condições, o presente artigo preserva Rebelo como "ruralista identificado" para se manter fiel à metodologia adotada por Costa (2012). Os demais são, indiscutivelmente, ruralistas, como salienta Costa (2012) e Cunha (2013).

O deputado ruralista Moacir Micheletto (PMDB/SP) foi escolhido presidente da Comissão e o cargo de relator ficou com o comunista Aldo Rebelo (PCdoB/SP).

\section{A votação na Comissão Especial do CFB/1965: deputados ruralistas e financiados pelo grande capital}

Em junho de 2010, Rebelo apresentou seu relatório, seguido por uma segunda versão, por meio do qual propunha um projeto de lei para substituir o $\mathrm{CFB} / 1965$. Ambos relatórios incorporaram diversas sugestões do agronegócio (CUNHA, 2013, p. 132-137) ${ }^{21}$.

No dia 06/07/2010, após várias críticas e ofensas entre parlamentares e manifestantes, a Comissão Especial aprovou o substitutivo alterado do deputado Rebelo: 18 deputados votaram naquela oportunidade, 13 a favor e 5 contra (CÂMARA DOS DEPUTADOS, 2011b).

Essa subseção sintetiza os dados levantados em Cunha (2013) a respeito do financiamento de campanha eleitoral dos 18 deputados que participaram da referida votação, que aprovou o texto embrionário que, em 2012, se tornaria a Nova Lei Florestal.

Com base na metodologia descrita na introdução, foram analisadas todas as contribuições para a campanha eleitoral de cada um dos 18 deputados que votaram naquela arena, referente às eleições de 2006, disponibilizadas na página eletrônica do Tribunal Superior Eleitoral (TSE). Assim, selecionou-se 136 pessoas jurídicas do agronegócio e interesses associados que financiaram as campanhas eleitorais de 2006 de 13 dos 18 deputados que participaram da votação do relatório Rebelo, na Comissão Especial do CFB/1965.

Considerando essa seleção e a triagem dos ruralistas, o Quadro 2, a seguir, mostra os 13 deputados que votaram a favor $(\mathrm{F})$ do relatório Rebelo e os 5 contrários (C). Essa análise revela, em linhas gerais, uma simetria entre a decisão do deputado de aprovar um projeto de lei com retrocessos ambientais e sua condição de ser ruralista e financiado pelo agronegócio, mostrando ainda que questões como pertencer ou não à base aliada do governo ou a determinado partido ou bloco parlamentar parecem não ter influenciado na decisão dos deputados daquela arena.

\footnotetext{
${ }^{21}$ O então presidente da Federação da Agricultura e Pecuária do Estado de São Paulo (Faesp), Fábio Meirelles, ao comentar o relatório do deputado Rebelo, declarou que o texto havia contemplado várias propostas da entidade. Fonte: <https://goo.gl/hX5piK>. Acesso em: 20 jul. 2010.
} 
QUADRO 2 - ANÁLISE DA VOTAÇÃO DO RELATÓRIO REBELO - COMISSÃO ESPECIAL TEMPORÁRIA DO CFB - 06 DE JULHO DE 2010

\begin{tabular}{|c|c|c|c|c|}
\hline & $\begin{array}{c}\text { Deputado } \\
\text { Partido/UF }\end{array}$ & $\begin{array}{c}\text { Votos } \\
\text { Favorável (F) } \\
\text { Contra }(\mathbf{C}) \\
\end{array}$ & $\underset{*}{\text { Ruralista }}$ & $\begin{array}{l}\text { Financiamento de } \\
\text { campanha pelo } \\
\text { agronegócio } * *\end{array}$ \\
\hline \multirow{9}{*}{ 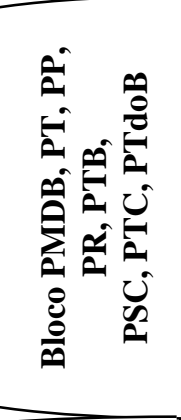 } & Anselmo de Jesus (PT/RO) & $\mathbf{F}$ & & - \\
\hline & Dr. Rosinha (PT/PR) & $\mathbf{C}$ & & - \\
\hline & Ernandes Amorim (PTB/RO) & $\mathbf{F}$ & - & - \\
\hline & Homero Pereira (PR/MT) & $\mathbf{F}$ & $\bullet$ & $\mathrm{X}$ \\
\hline & Luis Carlos Heinze (PP/RS) & $\mathbf{F}$ & $\bullet$ & $\mathrm{X}$ \\
\hline & Moacir Micheletto (PMDB/PR) & $\mathbf{F}$ & $\bullet$ & $\mathrm{X}$ \\
\hline & Reinold Stephanes (PMDB/PR) & $\mathbf{F}$ & & $X$ \\
\hline & Paulo Piau (PMDB/MG) & $\mathbf{F}$ & $\bullet$ & $\mathrm{X}$ \\
\hline & Valdir Colatto (PMDB/SC) & $\mathbf{F}$ & $\bullet$ & $\mathrm{X}$ \\
\hline \multirow{5}{*}{ 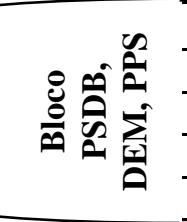 } & Cezar Silvestri (PPS/RS) & $\mathbf{F}$ & $\bullet$ & $X$ \\
\hline & Duarte Nogueira (PSDB/SP) & $\mathbf{F}$ & $\bullet$ & $\mathrm{X}$ \\
\hline & Marcos Montes (DEM/MG) & $\mathbf{F}$ & $\bullet$ & $\mathrm{X}$ \\
\hline & Moreira Mendes (PPS/RO) & $\mathbf{F}$ & $\bullet$ & $\mathrm{X}$ \\
\hline & Ricardo Tripoli (PSDB/SP) & $\mathbf{C}$ & & $\mathrm{X}$ \\
\hline \multirow{2}{*}{$\begin{array}{l}\text { PSB, PDT, } \\
\text { PCdoB, PNM } \\
\end{array}$} & Aldo Rebelo (PCdoB/SP) & $\mathbf{F}$ & 口 & $\mathrm{X}$ \\
\hline & Rodrigo Rollemberg (PSB/DF) & $\mathbf{C}$ & 口 & - \\
\hline PV & Sarney Filho (PV/MA) & $\mathbf{C}$ & & $\mathrm{X}$ \\
\hline PHS & Ivan Valente (PSOL/SP) & $\mathbf{C}$ & & - \\
\hline
\end{tabular}

- Parlamentar ruralista incluído na lista do Diap, segundo Costa (2012).

“"Parlamentar ruralista" identificado por Costa (2012) e fora da lista do Diap.

$\square$ Coalizão governo Lula (mar./2010 a dez./2010): PCdoB, PDT, PMDB, PP, PR, PRB, PSB, PT, PTB.

FONTE: Elaborado pelos autores. Dados extraídos de CÂMARA DOS DEPUTADOS (2009, 2011a, 2011b); PASQUARELLI (2011); COSTA (2012); TRIBUNAL SUPERIOR ELEITORAL (2006).

Depreende-se que dos 13 deputados que aprovaram o relatório Rebelo (Jesus, Amorim, Pereira, Heinze, Micheletto, Stephanes, Piau, Colatto, Silvestri, Nogueira, Montes, Mendes e Rebelo) (letra F, realçado em cinza): (i) 11 eram ruralistas ${ }^{22}$ pelos critérios de Costa (2012) e somente 2 não eram: Jesus e Stephanes ${ }^{23}$; (ii) 11 receberam doações do agronegócio e interesses associados na campanha eleitoral de 2006.

Por outro lado, dos 5 deputados que votaram contra o substitutivo de Rebelo (Rosinha, Tripoli, Sarney Filho, Valente e Rollemberg), somente Rodrigo Rollemberg (PSB/DF) é considerado ruralista “identificado", segundo Costa (2012, anexo C). No entanto, Rollemberg é reconhecido pelo seu

\footnotetext{
${ }^{22}$ Cunha $(2013,2015)$ mostra ainda que dos 13 deputados da Comissão Especial que votaram a favor do relatório Rebelo, 10 eram donos de terras (Jesus, Montes, Amorim, Micheletto, Mendes, Piau, Henzie, Silvestri, Pereira e Colatto), boa parte grandes propriedades, latifúndios improdutivos.

${ }^{23}$ Reinhold Stephanes pode não ser ruralista pelos critérios de Costa (2012), mas foi um defensor do agronegócio durante a revisão do CFB/1965. Em verdade, ele foi um apoiador ideológico dos ruralistas, como se vê em sua página na internet: <http://stephanes.com.br/>. Acesso em: 10 out. 2012.
} 
trabalho a favor da causa ambiental e foi elogiado pela sua atuação durante o processo político do CFB/1965, principalmente no Senado (junho a dezembro de 2011). Em vista disso, ao apontar Rollemberg como "ruralista", o presente trabalho o faz apenas para manter a coerência metodológica adotada, com base na lista de Costa (2012), mas leva-se em conta essa ressalva. ${ }^{24}$

Do grupo que votou contra o PL Rebelo, apenas 2 receberam doações de pessoas jurídicas ligadas ao agronegócio e interesses associados: Sarney Filho (PV/MA) e Ricardo Tripoli (PSDB/SP). Mas esses dois políticos eram reconhecidos como defensores da plataforma ambiental e dificilmente seriam favoráveis à redução da proteção florestal.

O Quadro 3, situado nas próximas páginas, esmiúça a apuração descrita anteriormente, citando as empresas do agronegócio e interesses associados que financiaram cada um dos políticos de tal arena e o respectivo valor doado. Além das doações do agronegócio, o quadro informa o montante de doações ocultas ${ }^{25}$ e aquelas classificadas como "outros”, que correspondem aos recursos próprios dos candidatos, às contribuições inferiores a $\mathrm{R} \$ 1.000,00$ feitas por pessoas jurídicas e as contribuições de qualquer valor oriundas de pessoas físicas, bem como doações recebidas de pessoas jurídicas pertencentes a setores distintos do agronegócio.

\footnotetext{
${ }^{24}$ Situação inversa é de Sarney Filho. Ele pertence à família Sarney, uma das mais poderosas do país, detentora de imóveis rurais e envolvida em situações fundiárias nebulosas, como descreve Castilho (2012, p. 61-62). Porém, além de ser identificado com a causa ambiental, Sarney Filho só declarou terrenos urbanos e por isso não foi incluído na lista de Costa (2012).

${ }^{25}$ Doações ocultas são aquelas feitas aos partidos políticos e repassadas aos candidatos. Apesar de legal, a prática não permite rastrear a origem do dinheiro repassado ao candidato, ou seja, se veio do fundo partidário provido pelo governo, se é fruto das contribuições pagas pelos filiados ou se foi doação de pessoa física ou jurídica para o partido.
} 
QUADRO 3 - DOAÇÕES DO AGRONEGÓCIO E INTERESSES ASSOCIADOS ÀS CAMPANHAS (2006) DOS DEPUTADOS QUE VOTARAM NA COMISSÃO ESPECIAL EM 6 DE JULHO DE 2010

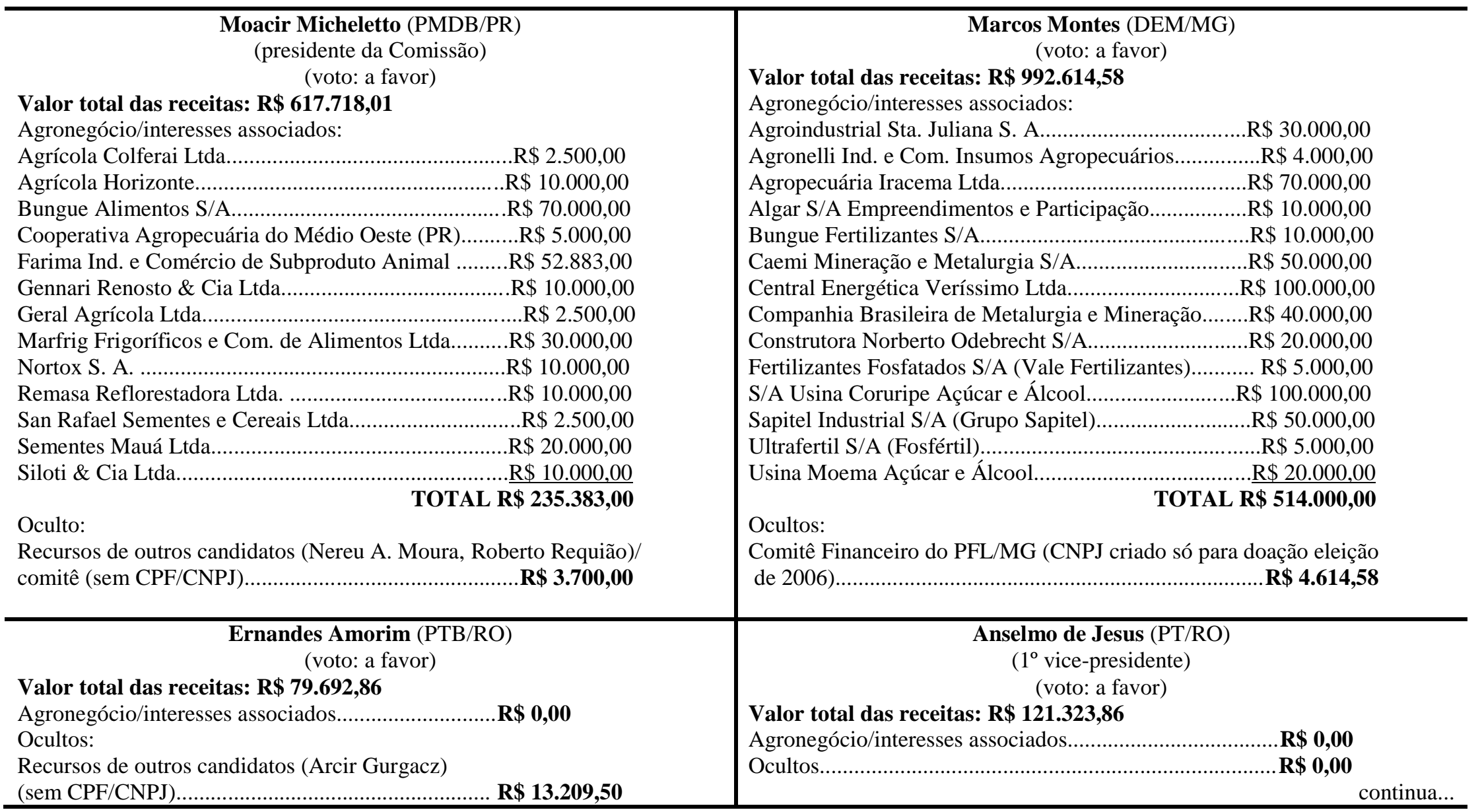

continuação 
QUADRO 3 - DOAÇÕES DO AGRONEGÓCIO E INTERESSES ASSOCIADOS ÀS CAMPANHAS (2006) DOS DEPUTADOS QUE VOTARAM NA COMISSÃO ESPECIAL EM 6 DE JULHO DE 2010

\begin{tabular}{|c|c|}
\hline $\begin{array}{c}\text { Luis Carlos Henzie (PP/RS) } \\
\text { (voto: a favor) }\end{array}$ & 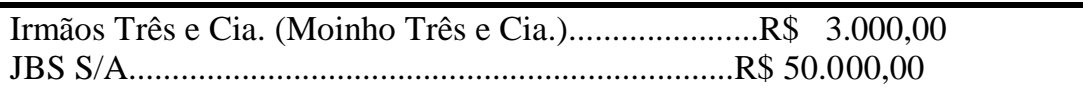 \\
\hline Valor total das receitas: $\mathrm{R} \$ \mathbf{9 9 4 . 4 1 4 , 5 9}$ & José Dinon e Filhos e Cia........................................... $\$$ 5.400,00 \\
\hline Agronegócio/interesses associados: & Klabin S/A \\
\hline Aeropel - Aero Operações Agrícolas Ltda.................R $\quad 4.100,00$ & 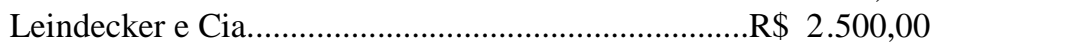 \\
\hline Agrogen S/A Agroindustrial................................... $\$ 10.000,00$ & Marasca Comércio de Cereais Ltda........................... $\$ 10.800,00$ \\
\hline Agropecuária Schwanck Ltda.................................... $\$$ 3.000,00 & Martins e Kissmann Ltda........................................ $\$ 2.000,00$ \\
\hline 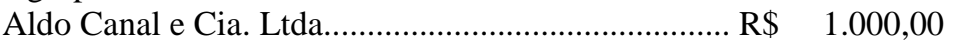 & Moinho Vacaria Industrial e Agrícola S/A................R $\$ 5.000,00$ \\
\hline Alliance One Brasil Exportadora de Tabacos Ltda....R $\$ 100.000,00$ & Moinho Estrela Ltda.................................... $\$ 10.000,00$ \\
\hline Alvorada Sistemas Agrícolas Ltda............................... $\$$ 1.000,00 & Moinhos Galopis Ltda............................................. $\$$ 2.000,00 \\
\hline 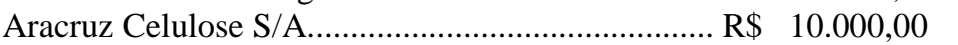 & 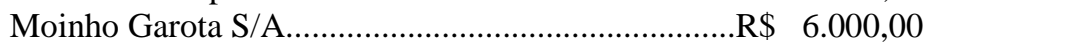 \\
\hline Bocchi Indústria e Com. Transp. Ben. Cereais Ltda.. $\mathrm{R} \$ \quad 2.000,00$ & Moinho Tomazzoni Ltda.......................................... $\$$ 3.000,00 \\
\hline Bolsa de Mercadorias \& Futuros................................ $\$ 30.000,00$ & Moinhos Vicato Ind. e Comércio Ltda.......................R $\quad 6.000,00$ \\
\hline Camera Agroalimentos S/A.................................... $\$$ 10.800,00 & 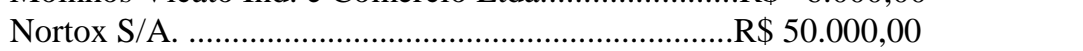 \\
\hline 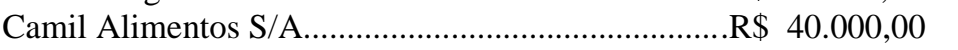 & Pileco Nobre Alimentos.............................................. $\$ 10.000,00$ \\
\hline Cerealista Seriema Ltda. ................................ $\$$ & 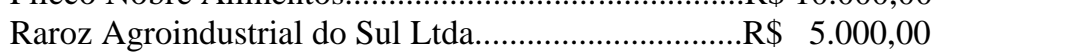 \\
\hline Cooperativa Agroindustrial Alegrette Ltda.............. $\mathrm{R} \$ \quad 3.000,00$ & Sapitel Industrial S/A (Grupo Sapitel)........................ $\$ 10.000,00$ \\
\hline Copagril Com. Agrícola Piccoli Ltda........................R\$ & 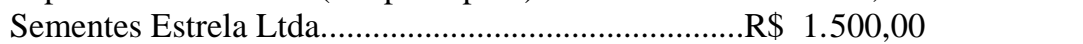 \\
\hline Coxilha Ind. Fertilizante e Corretivos Ltda.................. $\$ \quad 5.000,00$ & Stara S/A \\
\hline CTA Continental Tabaccos Alliance S/A.....................R $20.000,00$ & Stora Enso Brasil Ltda................................................ 15.770,16 \\
\hline 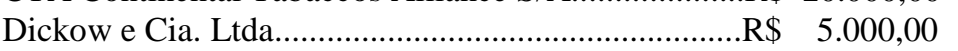 & Três Tentos Agroindustrial Ltda............................... \$ 10.800,00 \\
\hline Elio Starlick Ltda. (Gde. Spe. Sementes e Agron.).....R\$ & 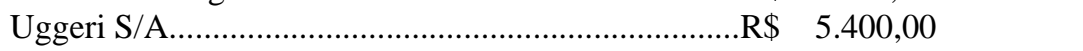 \\
\hline Engenho de Arroz São José Ltda.............................. $\$$ 5.000,00 & 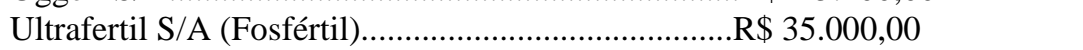 \\
\hline 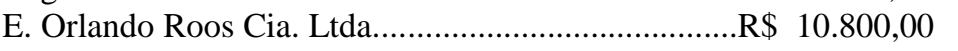 & Urbano Agroindustrial Ltda....................................... $\$ 35.000,00$ \\
\hline Euvax Participações Ltda......................................... $\$ 50.000,00$ & Viviana Alimentos Ltda...................................... $\$$ 6.000,00 \\
\hline Fertilizantes Fosfatados S/A (Vale Fertilizantes).......R $\$ 35.000,00$ & Votorantim Celulose e Papel (Fibria Celulose S/A)... $\underline{\mathrm{R} \$ 19.217,16}$ \\
\hline 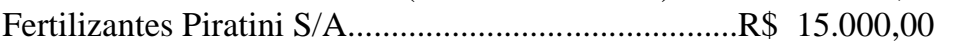 & TOTAL R\$703.667,32 \\
\hline 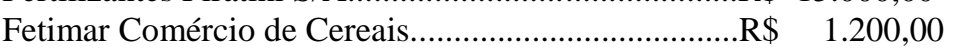 & Oculto: \\
\hline 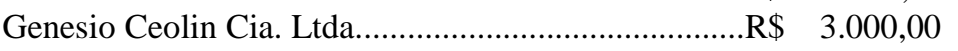 & Comitê Financeiro do Partido Progressista (PP) \\
\hline Germani Alimentos Ltda....................................... $\$$ & (CNPJ criado só para doação eleição de 2006)............. $\mathbf{R} \mathbf{2 . 4 4 5 , 2 8}$ \\
\hline Indústria Lezy de Implemento Agrícolas Ltda............R \$ & continua... \\
\hline
\end{tabular}
continuação. 
QUADRO 3 - DOAÇÕES DO AGRONEGÓCIO E INTERESSES ASSOCIADOS ÀS CAMPANHAS (2006) DOS DEPUTADOS QUE VOTARAM NA COMISSÃO ESPECIAL EM 6 DE JULHO DE 2010

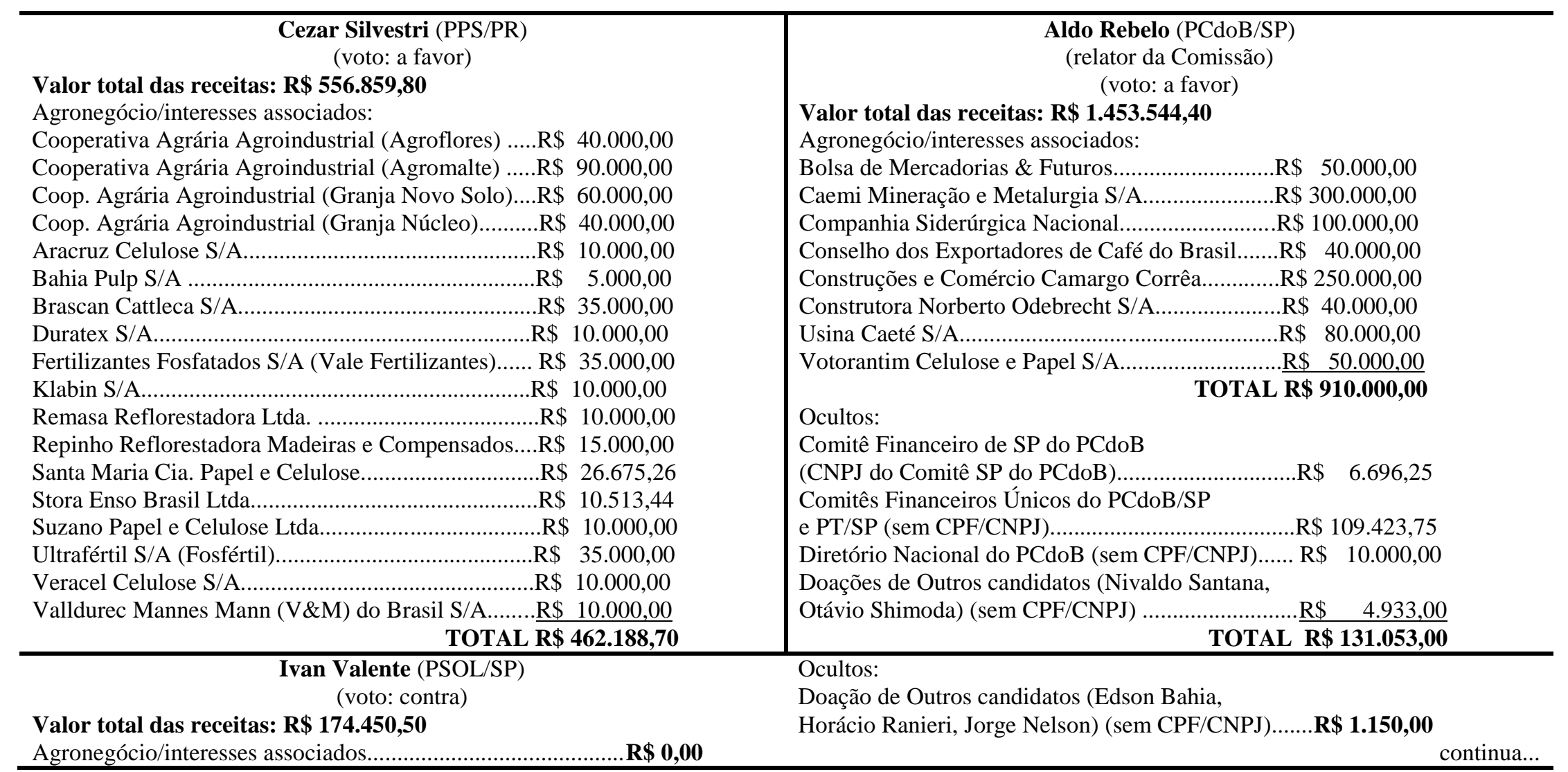

continuação. 
QUADRO 3 - DOAÇÕES DO AGRONEGÓCIO E INTERESSES ASSOCIADOS ÀS CAMPANHAS (2006) DOS DEPUTADOS QUE VOTARAM NA COMISSÃO ESPECIAL EM 6 DE JULHO DE 2010

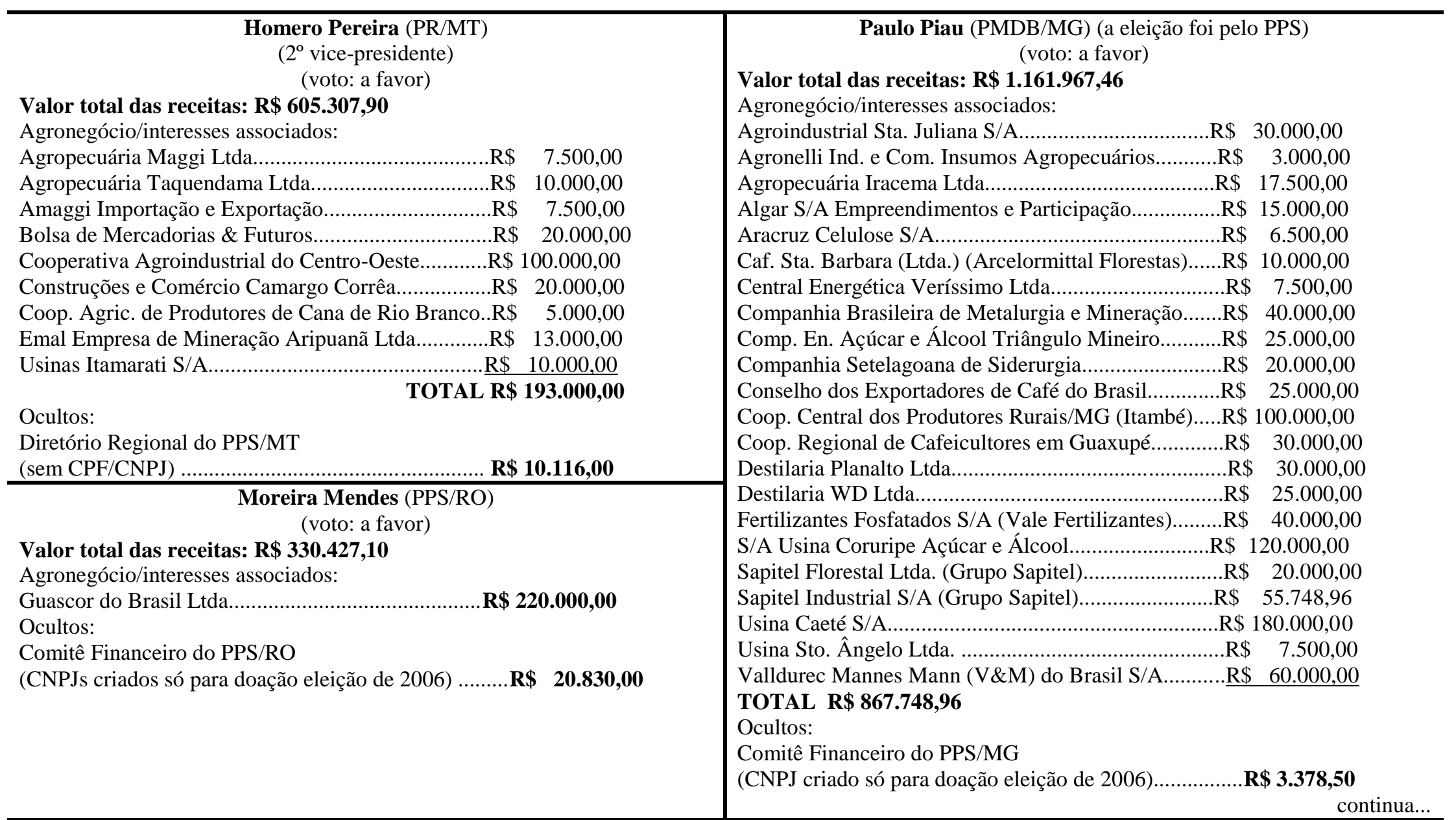

continuação. 
QUADRO 3 - DOAÇÕES DO AGRONEGÓCIO E INTERESSES ASSOCIADOS ÀS CAMPANHAS (2006) DOS DEPUTADOS QUE VOTARAM NA COMISSÃO ESPECIAL EM 6 DE JULHO DE 2010

\begin{tabular}{|c|c|}
\hline 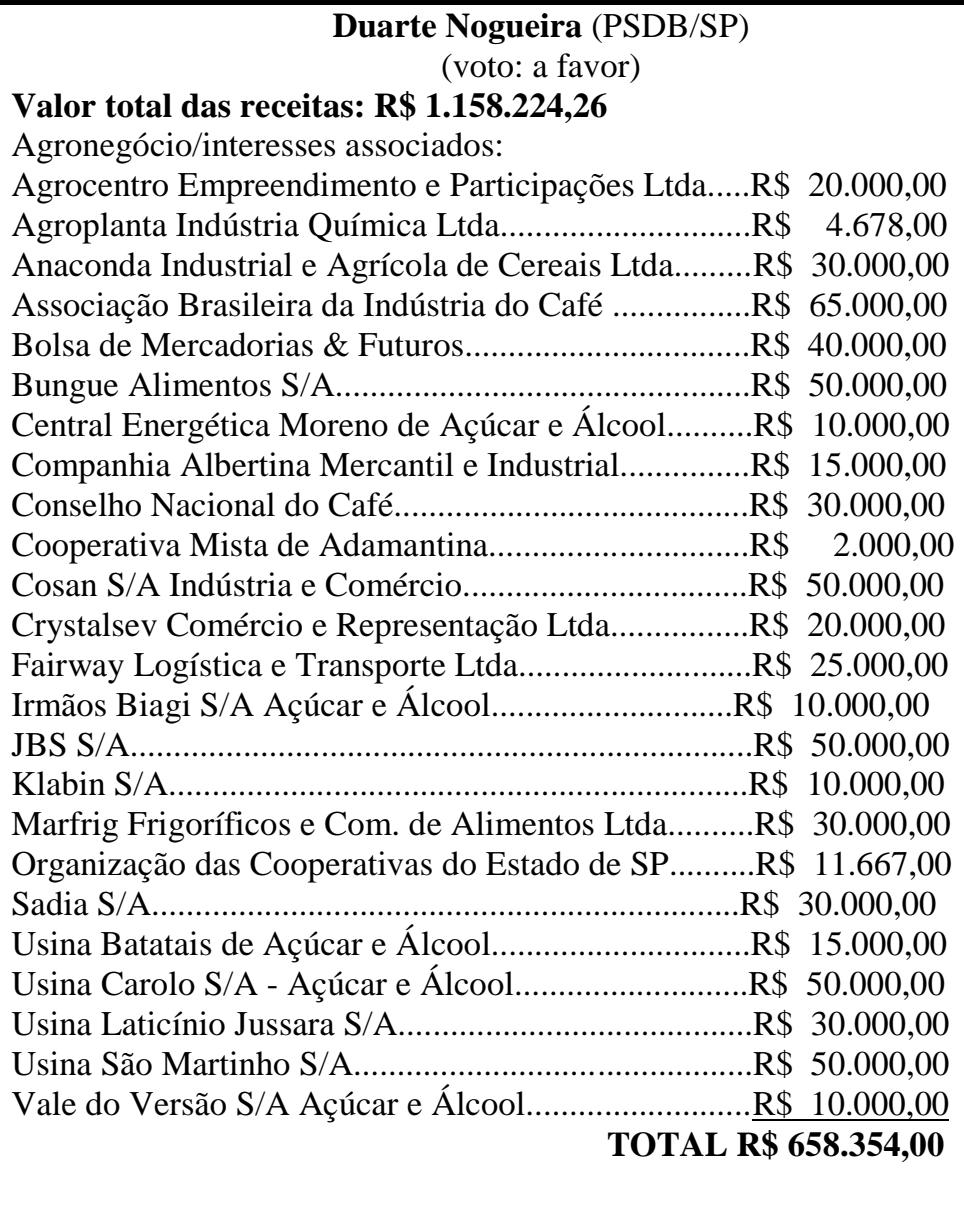 & 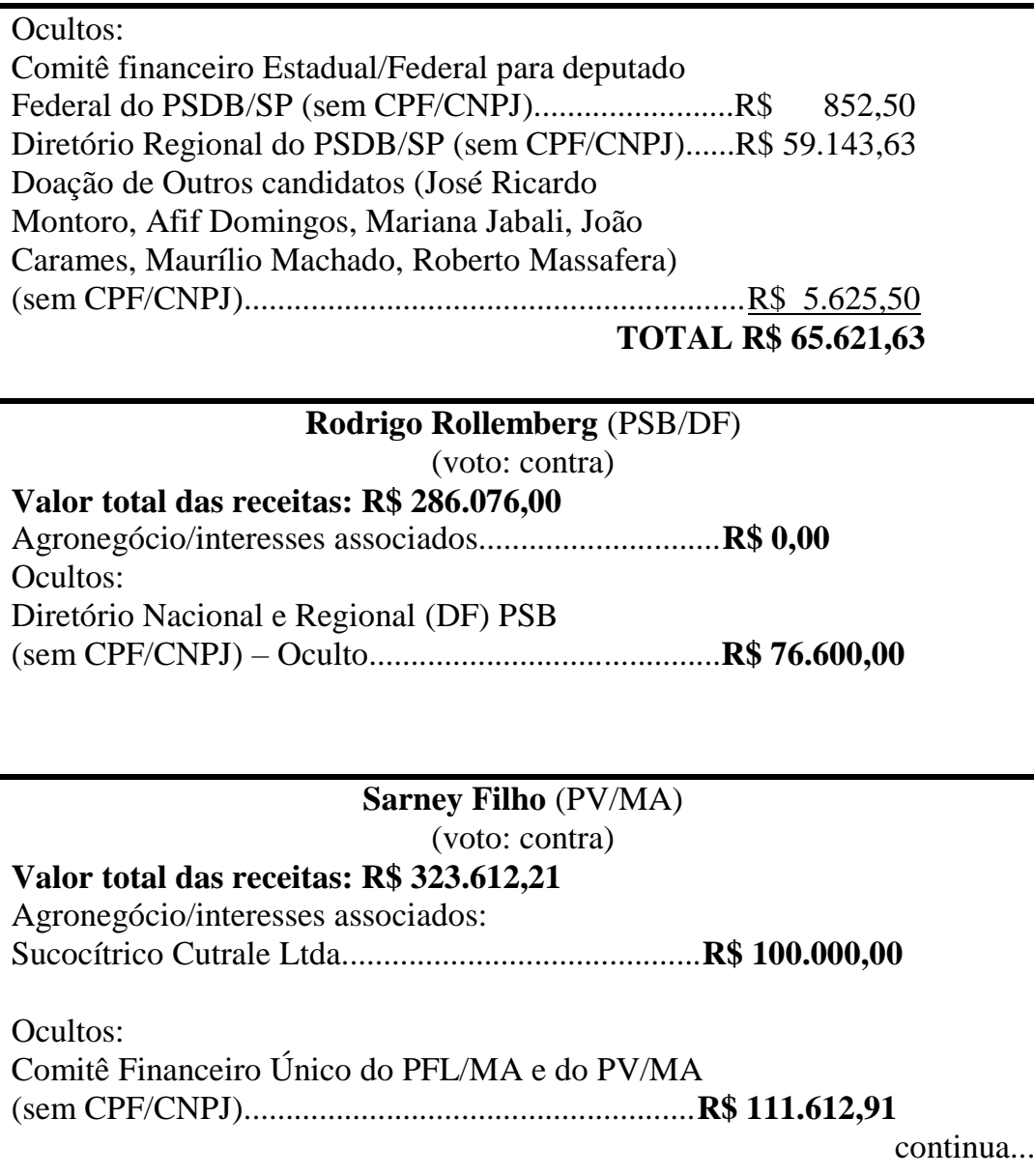 \\
\hline
\end{tabular}

continuação. 
QUADRO 3 - DOAÇÕES DO AGRONEGÓCIO E INTERESSES ASSOCIADOS ÀS CAMPANHAS (2006) DOS DEPUTADOS QUE VOTARAM NA COMISSÃO ESPECIAL EM 6 DE JULHO DE 2010

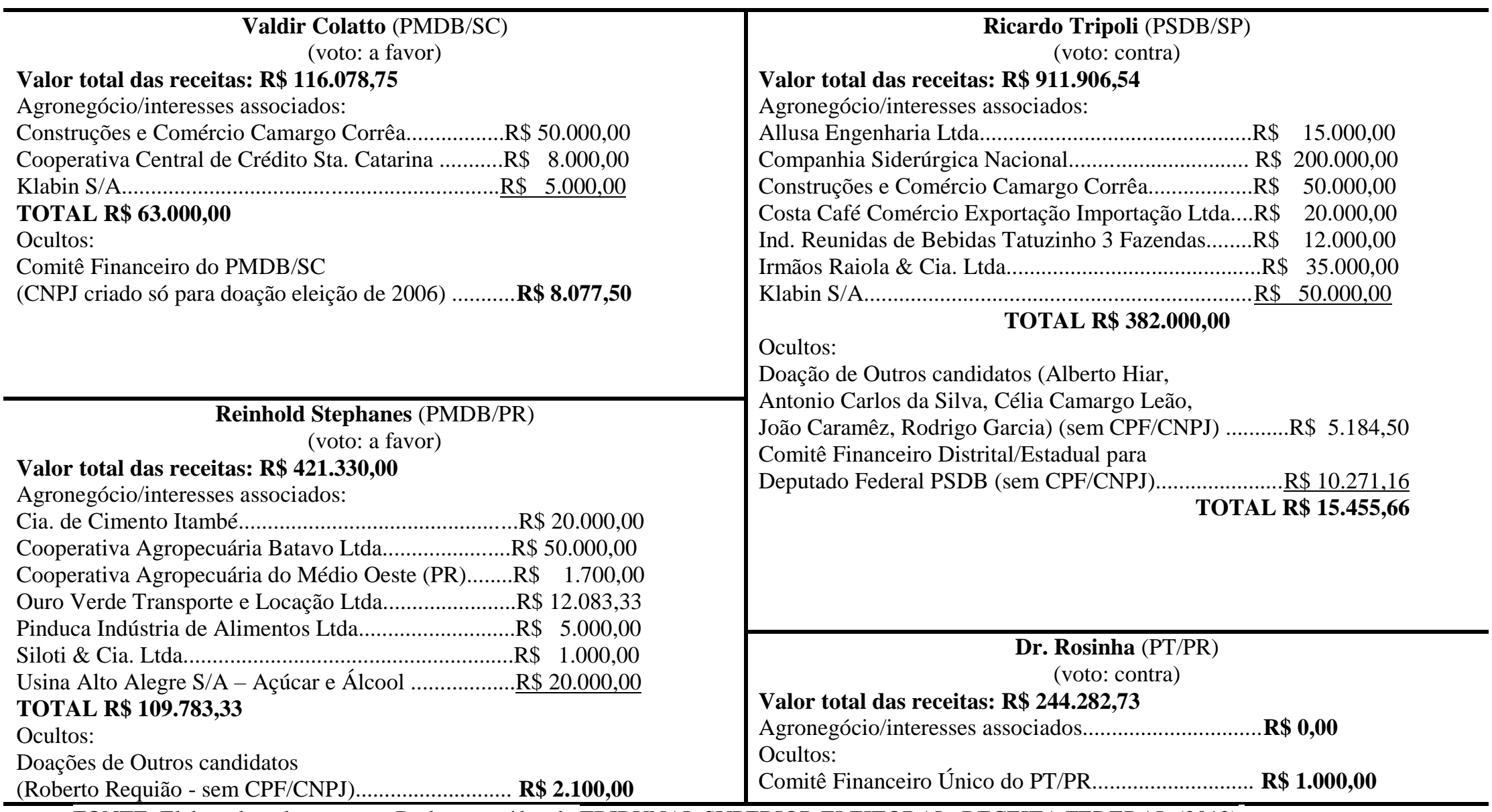

FONTE: Elaborado pelos autores. Dados extraídos de TRIBUNAL SUPERIOR ELEITORAL; RECEITA FEDERAL (2012). 
O Gráfico 2, a seguir, construído com dados retirados do Quadro 3, mostra as pessoas jurídicas do agronegócio e interesses associados que mais contribuíram para tais políticos. Como se pode observar, os valores não são desprezíveis:

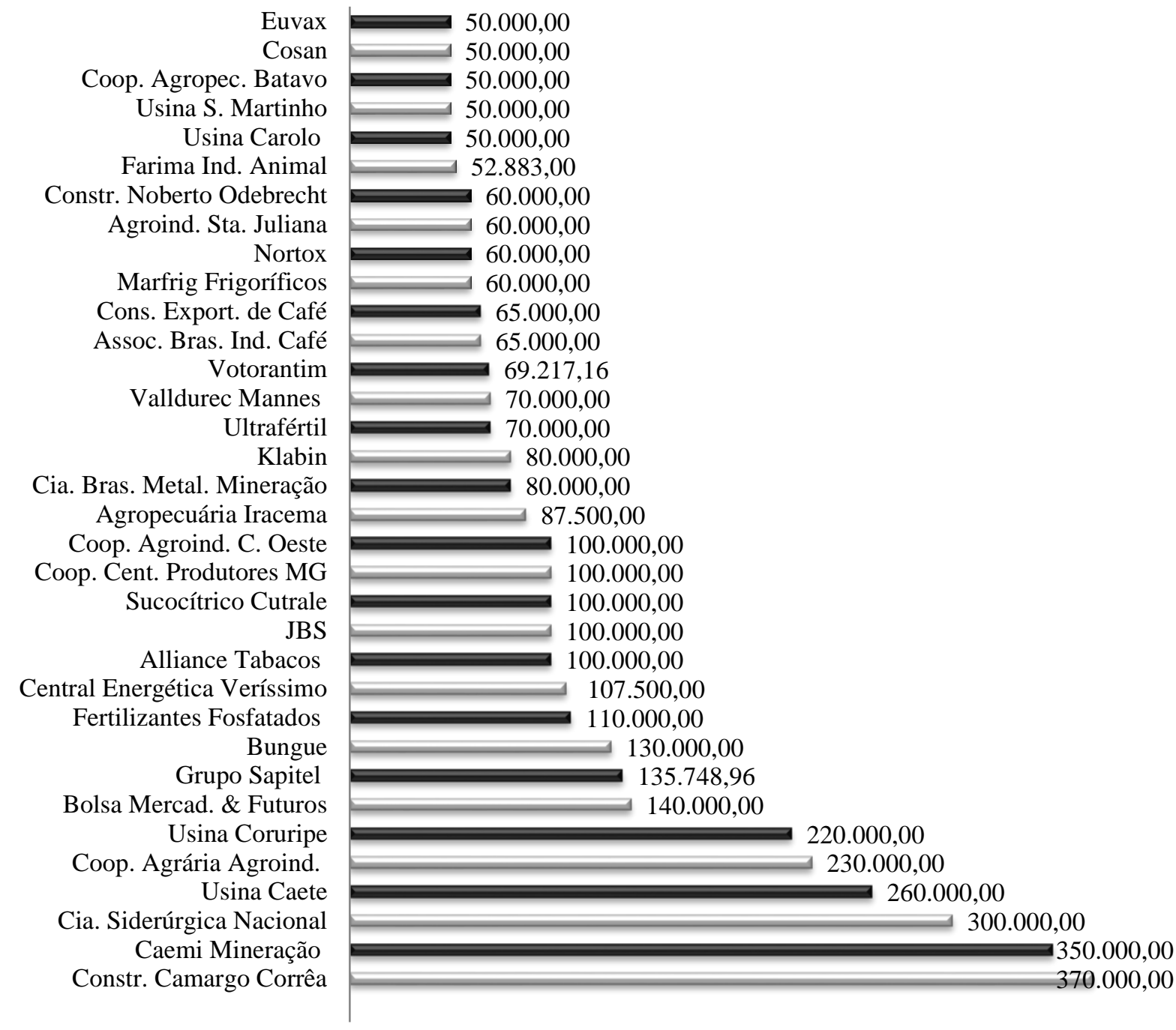

GRÁFICO 2 - MAIORES DOADORAS DO AGRONEGÓCIO E INTERESSES ASSOCIADOS NA CAMPANHA ELEITORAL (2006) DOS DEPUTADOS QUE PARTICIPARAM DA VOTAÇÃO DO RELATÓRIO REBELO EM JUL. DE 2010 (VALORES EM REAIS)

FONTE: Elaborado pelos autores. Dados extraídos de TRIBUNAL SUPERIOR ELEITORAL; RECEITA FEDERAL (2012).

Os Gráficos 3 e 4, a seguir, elaborados com dados pinçados do Quadro 3, comparam as doações feitas, respectivamente, ao grupo que votou a favor e contra o relatório Rebelo. As contribuições feitas pelo agronegócio e interesses associados (colunas vermelhas nos gráficos) são significativamente maiores no conjunto de deputados que votou a favor (Gráfico 3) do que no agrupamento de parlamentares que se posicionou contra (Gráfico 4). 


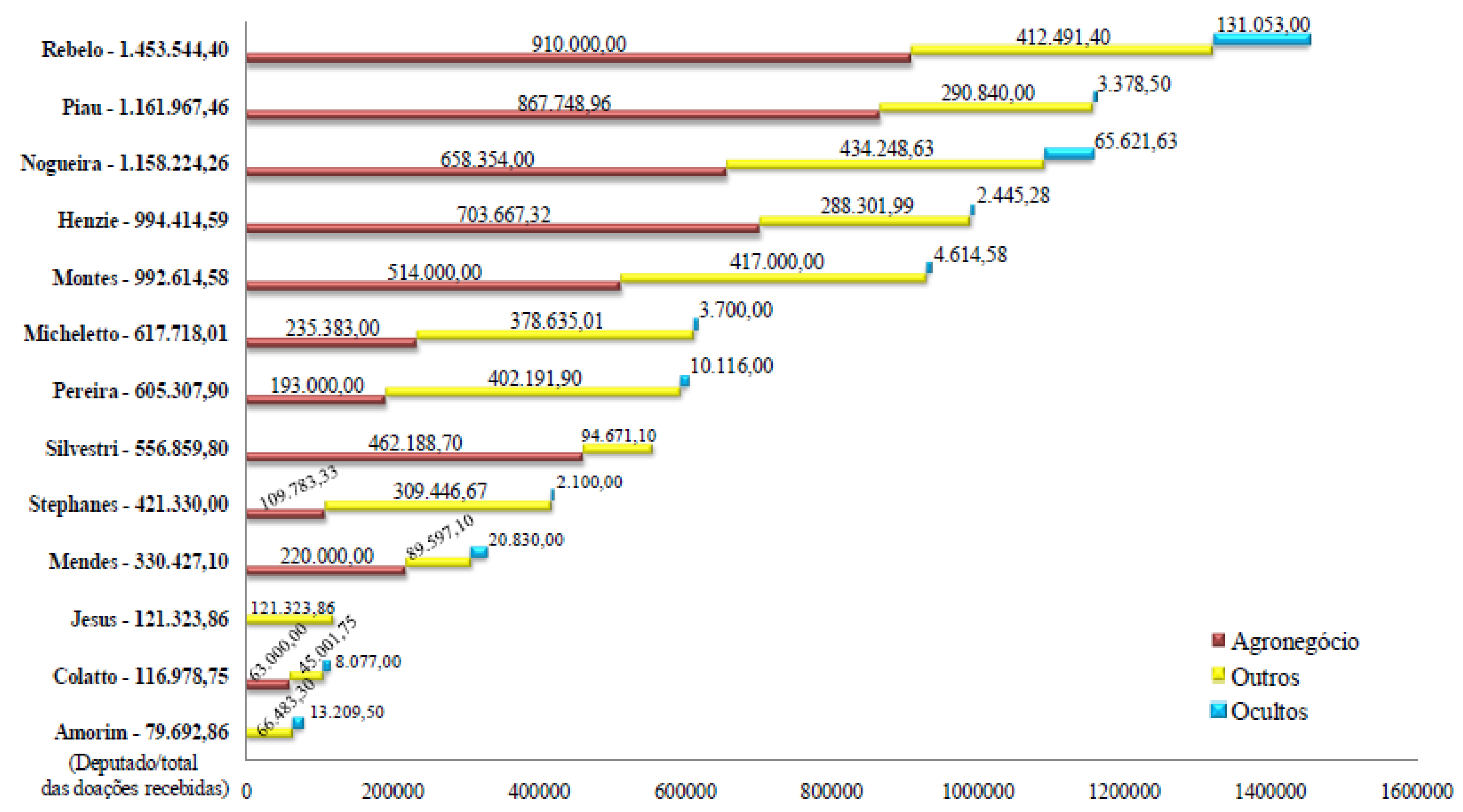

GRÁFICO 3 - DOAÇÕES DE CAMPANHA ELEITORAL (2006) AOS DEPUTADOS QUE VOTARAM A FAVOR NO SUBSTITUTIVO REBELO EM 6 DE JULHO DE 2010 (VALORES EM REAIS - R\$) 


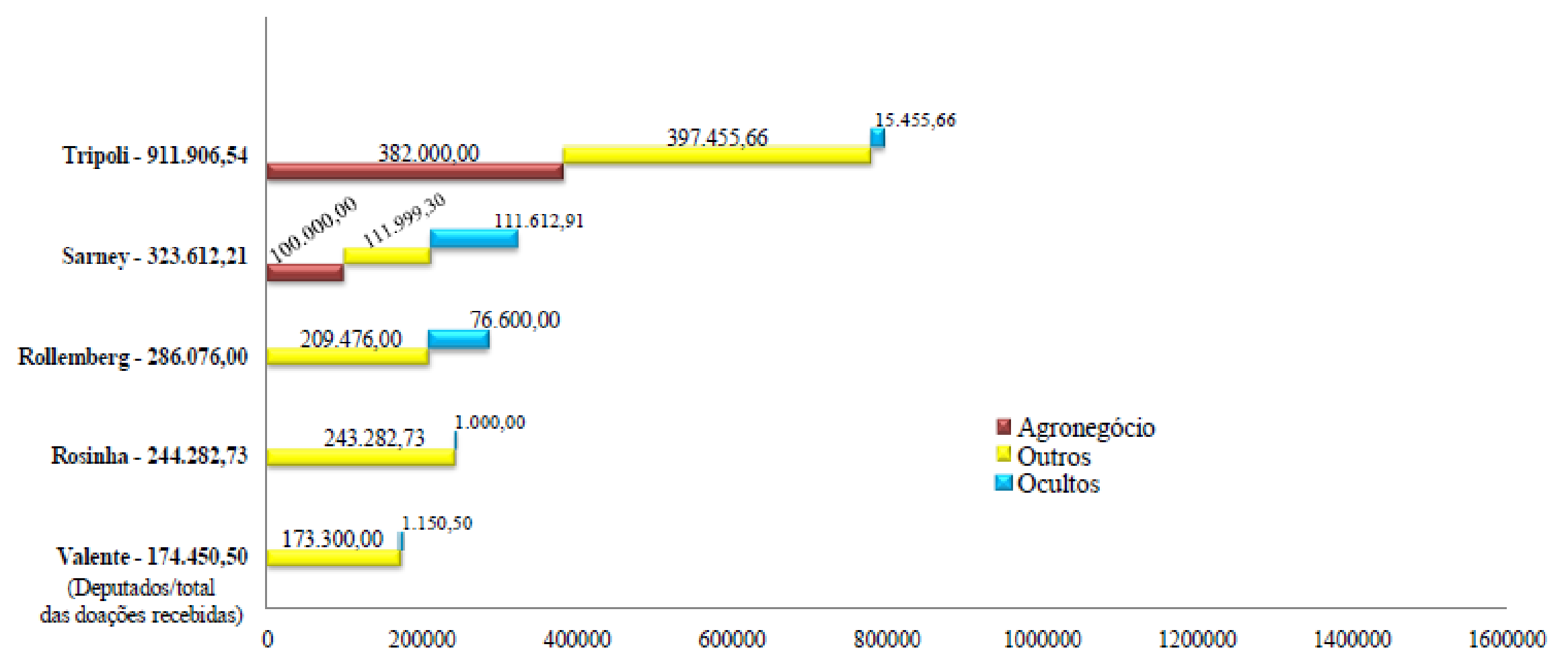

GRÁFICO 4 - DOAÇÕES DE CAMPANHA ELEITORAL (2006) AOS DEPUTADOS QUE VOTARAM CONTRA AO SUBSTITUTIVO REBELO EM 6 DE JULHO DE 2010 (VALORES EM REAIS - R\$)

FONTE: Elaborado pelos autores. Dados extraídos de TRIBUNAL SUPERIOR ELEITORAL (2012).

NOTA: o montante doado pelos setores denominados "interesses associados" está incluso no agronegócio. 
Mesmo proporcionalmente, o grupo dos 13 deputados favoráveis ao relatório de Rebelo recebeu mais contribuições do que os 5 que foram contrários. O Gráfico 5, a seguir, mostra que os 13 deputados que votaram a favor do texto auferiram quase $\mathrm{R} \$ 5$ milhões de doações oriundas de pessoas jurídicas do agronegócio e interesses associados (57\% do total de suas doações), enquanto os deputados contrários receberam somente $\mathrm{R} \$ 482$ mil desses mesmos setores (apenas 25\% do total de doações desse grupo).
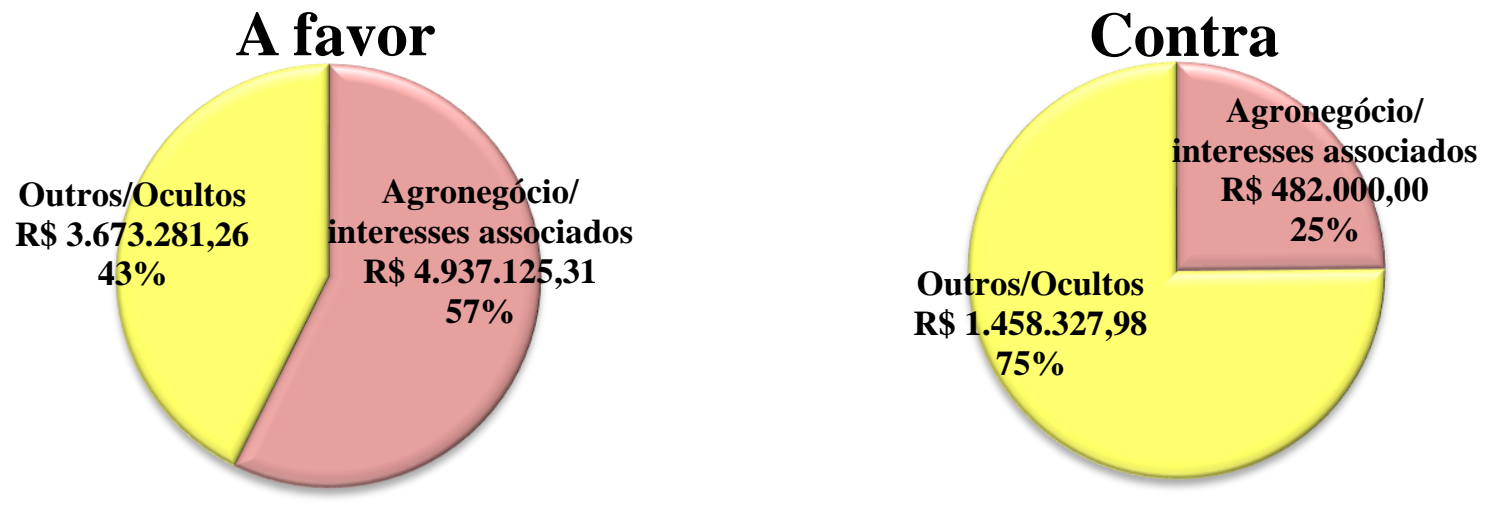

GRÁFICO 5 - ANÁLISE PROPORCIONAL DAS DOAÇÕES DE CAMPANHA ELEITORAL (2006) AOS DEPUTADOS QUE VOTARAM A FAVOR E CONTRA AO SUBSTITUTIVO REBELO, EM 06 DE JULHO DE 2010 FONTE: Elaborado pelos autores. Dados extraídos de: TRIBUNAL SUPERIOR ELEITORAL (2012). NOTA: O montante doado pelos interesses associados está incluso no agronegócio.

É visível: (i) a expressiva quantia doada por empresas e grupos do agronegócio e outros interesses associados aos ruralistas; (ii) a correspondência entre os deputados cujas campanhas receberam contribuições desses atores e os votos favoráveis a um projeto de lei que flexibilizava as exigências ambientais, beneficiando economicamente esses setores.

\section{Conclusões}

Pela abordagem do financiamento privado de campanhas eleitorais, o trabalho "agrega evidências" - nas palavras de Mancuso (2007, p. 102) - à hipótese de que o agronegócio e outros atores relacionados, aproveitando-se do desenho institucional então vigente, contribuíram para a revogação do CFB/1965 e para a criação Nova Lei Florestal. 
Mas não se pode concluir que as articulações desses setores econômicos, via financiamento de campanhas, influenciaram, por si só, a tomada de decisão que culminou numa política pública de grande retrocesso ambiental.

A convergência entre as preferências políticas de um ator ou grupo de interesse com o resultado vitorioso em um processo de política pública é condição necessária, mas não suficiente, para se afirmar que isso ocorreu pela influência (KLÜVER, 2013, p. 7).

Ou seja, afirmar que "a influência de um ator é a causa de uma decisão observada implica afirmar que aquela decisão não decorreu de outros fatores, e que, portanto, não teria acontecido - ou seria diferente - caso o ator não tivesse exercido sua influência" (MANCUSO, 2007, p. 123) ${ }^{26}$.

As decisões de uma política pública são o resultado de um processo que envolve a interação complexa de diversos elementos, sendo o financiamento de campanhas apenas uma das estratégias de mobilização dos atores econômicos (MANCUSO, 2007, p. 86-88).

Mas as correspondências apresentadas neste trabalho não podem ser desprezadas, afinal, pelo financiamento de campanhas eleitorais se pressupõe que os políticos apoiados, se eleitos, serão interlocutores dos doadores nas esferas de Poder. Trata-se, portanto, de um investimento, até porque, na esperança de doações futuras, os políticos se sentem naturalmente compelidos a aprovar demandas favoráveis aos seus investidores.

O trabalho também contribui para o debate a respeito da impertinência do financiamento privado de campanhas eleitorais que era adotado pelo Brasil. Esse sistema cooperou para o agronegócio ter uma expressiva representação política no Congresso Nacional, materializada pela bancada ruralista, como mostra Costa (2012). Por isso, é crível que as políticas públicas estão sujeitas à supremacia dos interesses econômicos desse setor sobre o interesse público, tal como ocorreu com o Código Florestal.

\section{Referências}

ABRANCHES, S. H. H. de. Presidencialismo de coalizão: o dilema institucional brasileiro. In: TAVARES, J. A. G. (Org.). O sistema partidário na consolidação da democracia brasileira. Brasília: Instituto Teotônio Vilela, 2003. p. 21-73 (Publicado originalmente em Dados, Revista de Ciências Sociais, v. 31, n. 01, 1988).

\footnotetext{
${ }^{26}$ Em verdade, existe um grande nível de exigência na avaliação do grau de influência política de um ator, pois mesmo com a utilização de indicadores, essa tarefa "continua sendo um fenômeno cuja ocorrência escapa em grande medida à apreensão dos cientistas sociais” (MANCUSO, 2007, p. 99).
} 
ARRUDA, Z. A. de. Onde está o agro deste negócio? Transformações socioespaciais em Mato Grosso decorrentes do agronegócio. 2007. 253f. Tese (Doutorado em Ciências - Análise Ambiental e Dinâmica Territorial) Programa de Pós-Graduação em Geografia da Universidade Estadual de Campinas, Campinas, 2007.

BENJAMIM, A. H.. Princípio da proibição de retrocesso ambiental. In: COMISSÃO DE MEIO AMBIENTE, DEFESA DO CONSUMIDOR E FISCALIZAÇÃO E CONTROLE. Princípio da proibição de retrocesso ambiental. Brasília: Senado Federal, 2012. p. 55-72.

BRASIL. Conselho Nacional do Meio Ambiente (Conama). Dispõe sobre os casos excepcionais, de utilidade pública, interesse social ou baixo impacto ambiental, que possibilitam a intervenção ou supressão de vegetação em Área de Preservação Permanente - APP. Resolução no 369, de 28 de março de 2006. Diário Oficial da União. Brasília, DF, nº 61, p. 150-151, 23 set. 2006.

BRASIL. Lei ${ }^{\circ} 12.651$, de 25 de maio de 2012. Dispõe sobre a proteção da vegetação nativa; altera as Leis $\mathrm{n}^{\text {os }} 6.938$, de 31 de agosto de 1981, 9.393, de 19 de dezembro de 1996, e 11.428, de 22 de dezembro de 2006; revoga as Leis $\mathrm{n}^{\text {os }} 4.771$, de 15 de setembro de 1965, e 7.754, de 14 de abril de 1989, e a Medida Provisória $\mathrm{n}_{-}^{\mathrm{o}} 2.166-67$, de 24 de agosto de 2001; e dá outras providências. Diário Oficial da União. Brasília, DF, 28 mai. 2012, p. 1.

CÂMARA DOS DEPUTADOS. Constituição da Comissão Especial destinada a proferir parecer ao Projeto de Lei $\mathbf{n}^{\circ}$ 1.876-A, de 2009, do deputado Sérgio Carvalho. Diário da Câmara dos Deputados, p. 53.544, Brasília, DF, 30 set. 2009.

CÂMARA DOS DEPUTADOS. Voto em separado dos deputados Sarney Filho e Edson Duarte, ambos do PV, ao Projeto de Lei no 1.876, de 1999, e apensos. Diário da Câmara dos Deputados, p. 37.390-37.438, Brasília, DF, 17 ago. 2010.

CÂMARA DOS DEPUTADOS. Conheça os Deputados. Disponível em: <http://www2.camara.gov.br/deputados/pesquisa/>. Acesso em: 30 nov. 2011.

CÂMARA DOS DEPUTADOS. Ficha de tramitação do Projeto de Lei $\mathbf{n}^{0}$ 1.876, de 1999, e apensos. Disponível em:

<http://www.camara.gov.br/proposicoesWeb/fichadetramitacao?id Proposicao=17338>. Acesso em: $01 \mathrm{dez} .2011$.

CÂMARA DOS DEPUTADOS. Tramitação do PL 1.876/1999. Disponível em:<http://www.camara.gov.br/proposicoesWeb/fichadetramitacao?idProposicao=1733.Acesso: 21 jun. 2012.

CASTILHO, A. L.. Partido da terra: como políticos conquistam o território brasileiro. São Paulo: Contexto, 2012.

COSTA, S. H. G.; OLIVEIRA, A. U.. Bancada ruralista no Nordeste: políticos, empresários ou "donos" de terra? In: Simpósio Internacional e Simpósio Nacional de Geografia Agrária - Questões agrárias na Panamazônia no século XXI: usos e abusos do território, 5 e 6, 2011, Belém. Anais... Belém: Editora Açaí, 2011.

COSTA, S. H. G.. Questão agrária do Brasil e a bancada ruralista do congresso nacional. 2012. 325 f. Dissertação (Mestrado) - Programa de Pós-graduação em Geografia Humana do Departamento 
de Geografia da Faculdade de Filosofia, Letras e Ciências Humanas da Universidade de São Paulo (USP). São Paulo, 2012.

CUNHA, P. R.. O Código Florestal e os processos de formulação do mecanismo de compensação de reserva legal (1996-2012): ambiente político e política ambiental. 2013. 255 f. Dissertação (Mestrado) - Programa de Pós-graduação em Ciência Ambiental (Procam) da Universidade de São Paulo (USP). São Paulo, 2013.

DEPARTAMENTO INTERSINDICAL DE ASSESSORIA PARLAMENTAR (DIAP). Radiografia do Novo Congresso - Legislatura 1999-2003. Brasília: Boletim do DIAP, ano VIII, nº 8, out. 1998.

DEPARTAMENTO INTERSINDICAL DE ASSESSORIA PARLAMENTAR (DIAP). Radiografia do Novo Congresso - Legislatura 2007-2011. Brasília: Série Estudos Políticos, ano IV, nov. 2006.

DYE, T. R. Understanding public policy. 11.ed. Upper Saddle, New Jersey: Prentice-Hall, 2005.

FERNANDES, B. M.. Questão agrária: conflitualidade e desenvolvimento territorial. In: BUAINAN, A. M. B. al. (Coords.). Luta pela terra, reforma agrária e gestão de conflitos no Brasil. Campinas: Unicamp, 2008. p. 173-230.

GANEN, R. S.; ARAÚJO, S. M. V. G. de. Revisão do Código Florestal: análise dos projetos de lei em tramitação no Congresso Nacional. In: TELES DA SILVA, S.; CUREAU, S.; LEUZINGER, M. D. (Orgs.). Código Florestal: desafios e perspectivas. São Paulo: Fiuza, 2010. p. 376-401.

GROSSMANN, E.; SAURUGGER, S.. Les groupes d'intérêt - Action collective et stratégies de représentation. Paris: Armand Colin Éditeur, 2006.

IRIGARAY, C. T. J. H.. Compensação de reserva legal: limites à sua implementação. In: BENJAMIN, A. H.; LECEY, E.; CAPELLI, S. (Orgs.). $\mathbf{1 2}^{\circ}$ Congresso Brasileiro de Direito Ambiental, 2007, São Paulo. Meio Ambiente e Acesso à Justiça. Flora, Reserva Legal e APP. São Paulo: Imprensa Oficial do Estado de São Paulo, 2007. v. 3. p. 53-64.

KLUYER, H.. Lobbyng in the European Union - Interest groups, lobbying coalitions, and policy change. Oxford: Oxford University Press, 2013.

LABRA, M. E.. Análise de políticas, modos de "policy-making” e intermediações de interesses: uma revisão. Phisis: Revista de Saúde Coletiva, Rio de Janeiro, v. 9, n.2, p. 131-166, 1999.

MANCUSO, W. P.. O lobby da indústria no Congresso Nacional: empresariado e política no Brasil contemporâneo. São Paulo: Humanitas: Edusp, 2007.

MANCUSO, W. P.; GONÇALVES, M. P.; MENCARINI, F.. Colcha de retalhos: a política de concessão de benefícios tributários ao empresariado no Brasil (1988-2006). In: PRALON, M.; LEOPOLDI, M. A. P.; IGLECIAS, W.. Estado, empresariado e desenvolvimento no Brasil: novas teorias, novas trajetórias. São Paulo: Editora de Cultura, 2010. v. 1, p. 213-237.

METZGER, J. P. O Código Florestal tem base científica? Natureza \& Conservação/Associação Brasileira de Ciência Ecológica e Conservação (ABECO). Editora Cubo, São Carlos/SP, v. 8, n.1, p. 1-8, 2010. 
NOGUEIRA, A. de C.. A (in)aplicabilidade do princípio a proibição de retrocesso ambiental no direito brasileiro. Revista Direito e Liberdade da Escola da Magistratura do Rio Grande do Norte, Esmaran, Natal, v. 15, n. 2, p. 09-32, maio/ago. 2013.

OLIVEIRA, A. U.. Modo de produção capitalista, agricultura e reforma agrária. São Paulo: Labour, 2007.

PASQUARELLI, B. V. L.. Formação de coalizões, apoio legislativo e atuação partidária no presidencialismo brasileiro. 2011. 138 f. Dissertação (Mestrado em Ciência Política) - Programa de Pós-graduação em Ciência Política, do Centro de Educação e Ciências Humanas da Universidade Federal de São Carlos, São Carlos, 2011.

RIBEIRO, R. M.. A questão agrária e territórios em disputa: embates políticos entre agronegócio e agricultura camponesa/familiar - década de 2000. 2009. 150 f. Dissertação (Mestrado em Geografia) - Programa de Pós-graduação em Geografia da Universidade Federal de Uberlândia (Instituto de Geografia), Uberlândia, Minas Gerais, 2009.

SILVA, J. A. A.; NOBRE, A. D.; MANZATTO, C. V.; JOLY, C. A.; RODRIGUES, R. R.; SKORUPA, L. A.; NOBRE, C. A.; AHRENS, S.; MAY, P. H.; SÁ, T. D. de A.; CUNHA, M. M. L. C. da; RECH FILHO, E. L.. O Código Florestal e a ciência: contribuições para o diálogo. São Paulo: Sociedade Brasileira para o Progresso da Ciência, SBPC; Academia Brasileira de Ciências, ABC. 2011.

SOARES-FILHO, B. S.. Impacto da Revisão do Código Florestal: como viabilizar o grande desafio adiante? Secretaria de Assuntos Estratégicos do Governo Federal e Centro de Sensoriamento Remoto da Universidade Federal de Minas Gerais. 2013.

SOUZA, C.. Estado do campo da pesquisa em políticas públicas no Brasil. Revista Brasileira de Ciências Sociais, Rio de Janeiro, v. 18, n. 51, p. 15-20, fev. 2003.

SPAROVEK, G.; BARRETO, A.; KLUG, I.; PAPP, L.; LINO, J.. A revisão do Código Florestal brasileiro. Revista Novos Estudos, São Paulo, n. 89, p. 111-135, mar. 2011.

TELLES DO VALLE, R. S.. Código Florestal: mudar é preciso. Mas para onde? In: TELES DA SILVA, S.; CUREAU, S.; LEUZINGER, M. D. (Orgs.). Código Florestal: desafios e perspectivas. São Paulo: Fiuza, 2010. p. 346-375.

THOMAS, C.. Introduction: the study of interest groups. In: THOMAS, C. (Org.). Research guide to U.S. and international interest groups. Westport: Praeger Publishers, 2004. p. 1-23.

Artigo recebido em 12/11/2017. Aceito para publicação em 19/12/2017. 